\title{
Birth-Related Perineal Trauma in Low- and Middle-Income Countries: A Systematic Review and Meta-analysis
}

\author{
Magda Aguiar ${ }^{1,4}$ (1) $\cdot$ Amanda Farley $^{1} \cdot$ Lucy Hope $^{2,3} \cdot$ Adeela Amin $^{1} \cdot$ Pooja Shah $^{1} \cdot$ Semira Manaseki-Holland $^{1}$
}

Published online: 26 March 2019

(c) The Author(s) 2019

\begin{abstract}
Introduction Birth-related perineal trauma (BPT) is a common consequence of vaginal births. When poorly managed, BPT can result in increased morbidity and mortality due to infections, haemorrhage, and incontinence. This review aims to collect data on rates of BPT in low- and middle-income countries (LMICs), through a systematic review and meta-analysis. Methods The following databases were searched: Medline, Embase, Latin American and Caribbean Health Sciences Literature (LILACs), and the World Health Organization (WHO) regional databases, from 2004 to 2016. Cross-sectional data on the proportion of vaginal births that resulted in episiotomy, second degree tears or obstetric anal sphincter injuries (OASI) were extracted from studies carried out in LMICs by two independent reviewers. Estimates were meta-analysed using a random effects model; results were presented by type of BPT, parity, and mode of birth. Results Of the 1182 citations reviewed, 74 studies providing data on 334,054 births in 41 countries were included. Five studies reported outcomes of births in the community. In LMICs, the overall rates of BPT were 46\% (95\% CI 36-55\%), 24\% (95\% CI 17-32\%), and 1.4\% (95\% CI $1.2-1.7 \%$ ) for episiotomies, second degree tears, and OASI, respectively. Studies were highly heterogeneous with respect to study design and population. The overall reporting quality was inadequate. Discussion Compared to high-income settings, episiotomy rates are high in LMIC medical facilities. There is an urgent need to improve reporting of BPT in LMICs particularly with regards to births taking in community settings.
\end{abstract}

Keywords Episiotomy $\cdot$ OASI $\cdot$ Birth-related perineal trauma $\cdot$ Systematic review $\cdot$ LMICs

Electronic supplementary material The online version of this article (https://doi.org/10.1007/s10995-019-02732-5) contains supplementary material, which is available to authorized users.

Semira Manaseki-Holland

s.manasekiholland@bham.ac.uk

Magda Aguiar

magda.aguiar@ubc.ca

1 Institute of Applied Health Research, University of Birmingham, Birmingham, UK

2 Institute of Metabolism and Systems Research, College of Medical and Dental Sciences, University of Birmingham, Birmingham, UK

3 Present Address: Department of Nursing and Midwifery, Institute of Health \& Society, University of Worcester, Worcester, UK

4 Faculty of Pharmaceutical Sciences, University of British Columbia, Vancouver, BC, Canada

\section{Significance}

What is already known on this subject? Birth-related perineal trauma is a common complication of vaginal childbirth. Adequate management reduces morbidity and improves maternal health and wellbeing. Women in LMICs are thought to be at a higher risk of perineal trauma. What this study adds? Women in LMICs are at higher risk for episiotomy, but not for the spontaneous second degree tear and OASI. Better reporting practices and more evidence from the community are needed to provide a more accurate picture of the burden of BPT in LMICs.

\section{Introduction}

Maternal health is critical in many countries of the world, and the World Health Organization (WHO 2018) estimates that $99 \%$ of maternal deaths happen in low- and middleincome countries (LMICs). However, death is only the "tip 
of the iceberg" that surfaces a devastating plethora of conditions affecting the health and wellbeing of mothers living in resource-poor settings. A report from the Safe Motherhood initiative, a partnership between the WHO, the World Bank, and other international organisations that aims to improve maternal and new-borns' health in LMICs, estimated that for every mother who dies, 30-50 women suffer injury, infection, or disease (Islam 2007). While the burden of BPT in LMICs is not known, studies in high-income settings show that the majority of women who have a vaginal birth experience some form of BPT (Christine Kettle et al. 2012; Chris; Kettle and Tohill 2008). BPT refers to any injury to the perineum that happens during childbirth. BPT can happen as a spontaneous tear due to pressure on the perineum when the baby is delivered vaginally, or as a surgical cut, known as episiotomy, that aims facilitate vaginal birth and prevent severe spontaneous tears (Carroli and Mignini 2009; Royal College of Midwives 2012). Spontaneous BPT is classified as a first degree tear if there is only injury to the skin; second degree tear if there is injury to the skin and the muscle tissue; and obstetric anal sphincter injuries (OASI), which include third and four degree tears, if the injury extends to the anal sphincter (Chris Kettle and Tohill 2008). The main risk factors for BPT include maternal age, parity, use of forceps, birthweight, and prolonged second stage labour (Smith et al. 2013). Inadequate management of BPT can lead to severe complications. Acute complications include haemorrhage and puerperal sepsis, which are major causes of death in LMIC, while chronic complications include pelvic floor disorders, such as urinary and faecal incontinence (Huebner et al. 2013; Poen et al. 1998) persistent pain, dyspareunia, and prolapse (Elharmeel et al. 2011; WHO 2003).

Episiotomy and OASI rates are commonly used as quality indicators of health systems and health care (WHO 2016). Misdiagnose and underreporting of perineal tears have been cited as the main barriers to the improvement of BPT management and morbidity-related outcomes in Europe (Blondel et al. 2016). The same is likely to occur in LMICs, with even more devastating impact on health and wellbeing. Young women suffering from chronic incontinence and dyspareunia suffer from lower quality of life and self-esteem (Sinclair and Ramsay 2011). Socially, these conditions create a hostile environment stigma, isolation and rejection by the husband and the community, in turn leading to emotional burden and shame (Mota 2017). Although the actual numbers are not known, it is speculated that BPT affects millions per year around the world, who suffer with its consequences in silence (WHO 2009).

The high rate of community deliveries by untrained birth attendants (UNICEF 2008), the young maternal age at first pregnancy, and the high rates of episiotomies in hospitals, led us to hypothesise that women in LMICs are at a higher risk of BPT. The risk of complications associated with BPT is also likely to be increased in poorer settings due to the limited access to the adequate resources such as optimal suturing materials, poor environmental and household circumstances, lack of sanitation, and malnutrition (UNICEF 2008). In view of the above, there is an urgent need to understand the scale and characteristics of the problem in LMICs. Hence, the aim of this systematic review was to summarise data on the use of episiotomy and the frequency of spontaneous significant BPT (second degree and OASI) in LMICs.

\section{Methods}

This review follows the Preferred Reporting Items for Systematic Reviews and Meta-Analyses (PRISMA) and the Meta-Analysis of Observational Studies in Epidemiology (MOOSE) (Moher et al. 2010; Stroup et al. 2000). The protocol has been published elsewhere (Aguiar et al. 2013). Searches were conducted in the following electronic databases: Embase (1996-2016); Medline, (1996-2016), Lilacs and the WHO's regional databases (African Index Medicus, Index Medicus for the Eastern Mediterranean Region, Index Medicus for South-east Asian Region and Western Pacific Region Index Medicus), and took place in February/March 2014 and updated in February 2016. Search strategies (supplementary material) were constructed by combining MeSH terms and key words relating to the perineum, childbirth, episiotomy, and low and middle income countries. We also searched reference lists of the included studies and performed google searches to identify unpublished work.

\section{Study Eligibility}

Studies were included in the review if they (1) reported data on the proportion of vaginal births resulting in perineal trauma (episiotomy, second degree trauma and OASI); (2) were conducted in a LMIC as defined by the World Bank (2014); (3) reported data from 2004 to 2016 (this time-frame was chosen to maximize the relevance for current clinical practice and policy recommendations). All study designs were considered, as long as cross-sectional data were available. In interventional studies, data were retrieved from the usual care arm.

\section{Study Identification and Data Extraction}

Eligible studies were identified by a two stage screening process. Firstly, two reviewers independently screened titles and abstracts (MA and LH) and secondly, the full texts of the potentially relevant studies were screened (MA, AA and PS). Data were extracted independently and in duplicate using a predesigned data extraction form (see supplementary material). We extracted data regarding the study setting 
and design, recruitment method, parity, and characteristics of included participants. Any discrepancies during screening or data extraction were resolved through discussion or through the input of a clinical reviewer (SMH) if consensus could not be reached.

\section{Quality Assessment}

The quality of included studies was assessed by two reviewers (MA and PS) using a bespoke tool based on Looney's critical appraisal instrument for systematic reviews of incidence and prevalence studies (Loney et al. 1998) and the WHO systematic review of severe acute maternal morbidity (Gülmezoglu et al. 2004). Quality was based on definition of perineal trauma, sample size, loss of data, and adequacy of description of the population's characteristics (supplementary material).

\section{Statistical Analysis}

Estimates of the proportion of vaginal births that resulted in BPT were pooled by the different types of BPT (episiotomy, second degree tears and OASI) using a random effects model. Random effects was chosen due to expected high clinical and statistical heterogeneity (determined by $I^{2}$ statistic $>75 \%$ ). (Nyaga et al. 2014). Sub-group analyses by parity and delivery mode (spontaneous or operative vaginal birth) were also performed and presented in supplementing material.

\section{Results}

\section{Identification of Studies}

A total of 1182 studies were identified. After duplicates were removed $(n=340)$, the remaining 842 articles were screened for eligibility based on their title and abstract. The full text of 240 studies were assessed and of these, 74 studies were included (Fig. 1).

A summary of characteristics of included studies is provided in Table 1. This review provides data from 41 LMICs, the majority being lower-middle $(n=19)$ and upper-middle income $(n=16)$ countries. Studies varied in their designs
Fig. 1 Flow diagram of the study selection process

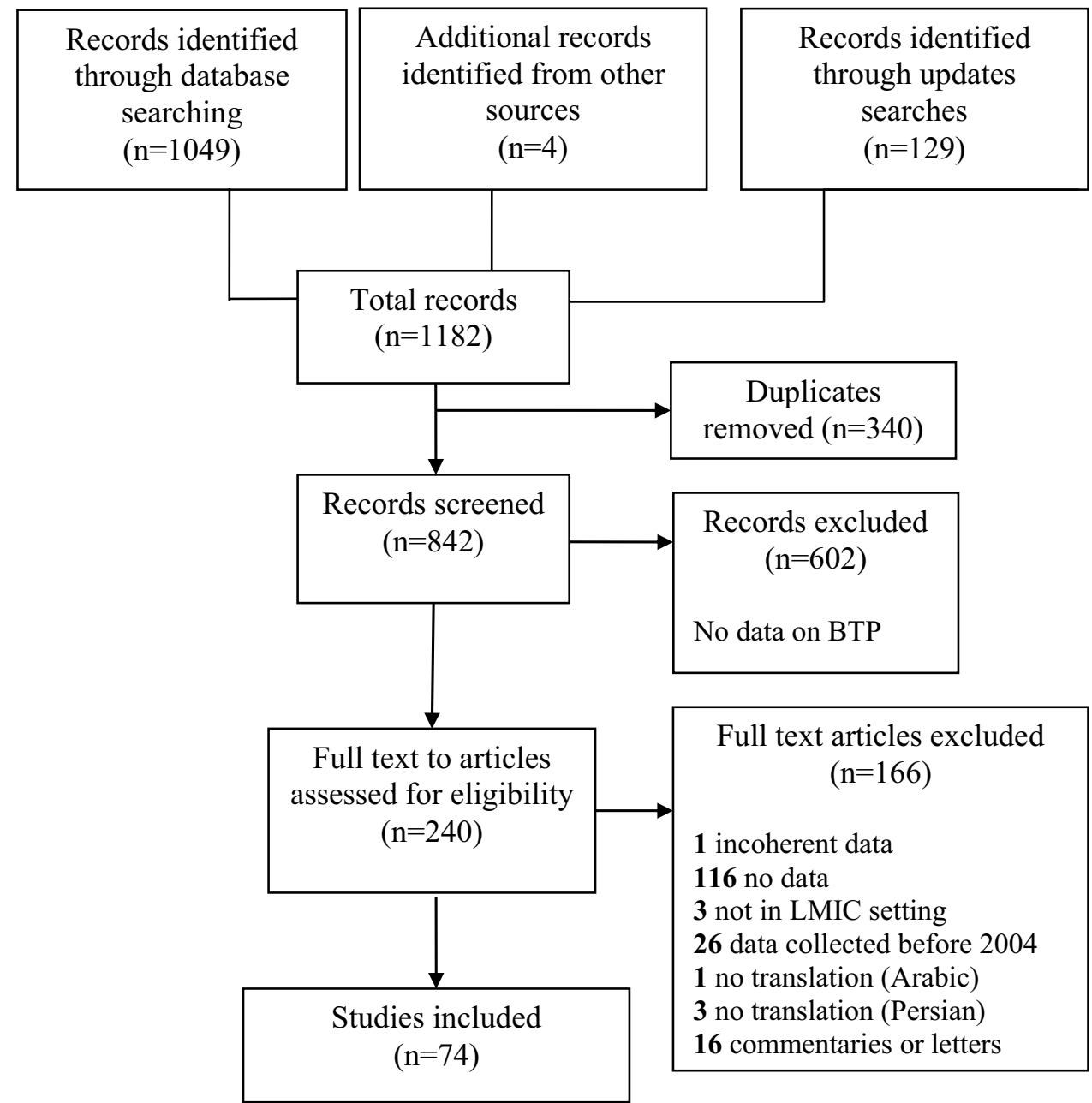


with most being cross-sectional $(n=27)$. There were also cohort studies $(n=20)$, RCTs $(n=15)$, and non-randomised interventional studies $(n=6)$. Several studies provided data on more than one type of BPT. Overall, this review found 118 BPT estimates, of which 46 were episiotomies, $13 \mathrm{~s}$ degree trauma, 42 OASI, and 16 were not specified (NS).

The majority of the studies reported episiotomy data $(n=46)$ and were set in medical facilities $(n=69)$. Three studies reported combined results of births in medical facilities and in the community (Assarag et al. 2013; Gözükara et al. 2015; Iyengar 2012) and one study, by Koettker et al. (2012), focus on planned home births with women with low risk pregnancies. Most studies' population were healthy primiparous women with singleton pregnancies. Several studies $(N=68)$ included women of various parities. Those studies that did not stratify the outcome by parity were classified as having a mixed-parity population. The main characteristics of each of the included studies are provided in Table 2. A few studies focused on specific sub-groups of the population: breastfeeding mothers, (Nguyen et al. 2013) multiparous women, (Reyes 2011) women subjected to female genital mutilation (Kaplan et al. 2013; Ndiaye et al. 2010), prolonged second stage of labour (Colacioppo and Gonzalez Riesco 2009) and birth of a macrocosmic foetus (Chaabane et al. 2013). Others focused on different birth techniques or settings: operative vaginal births, (Baloch et al. 2008; Carvalho et al. 2010; Khaskheli et al. 2012; Waheed et al. 2012) supine birthing position (Aguilar et al. 2013) and planned home birth for low risk pregnancies (Koettker et al. 2012).

Overall, the meta-analysis estimated that $46 \%$ (95\% CI 35-55\%) of vaginal births in LMICs were facilitated by an episiotomy (Fig. 2). A sub-group analysis by parity showed that primiparous women were at higher risk for episiotomy, $62 \%$ (95\% CI 40-84\%), compared to mixed parity populations 33\% (95\% CI 22-45\%), and multiparous population $25 \%$ (CI 21-30\%). The overwhelming majority of these births happened in medical facilities.

A representation of the meta-analysis results by country (Fig. 3) shows that reported rates of episiotomy were generally higher in the Asian continent, nevertheless, data were lacking for the majority of LMICs. The highest pooled estimates were in Pakistan, with 98\% (CI 93-99\%), and the lowest in Cameroon, with 10\% (CI 9-11\%).

The overall reported rate of spontaneous second degree tears was 23\% (95\% CI 16-29\%) (Fig. 3). The frequency of second degree tears was higher in studies reporting on primiparous women, $32 \%$ (95\% CI 11-52\%), compared to mixed parity populations, $3 \%$ (95\% CI 1-4\%) (Fig. 4).

Following a similar trend, OASI occurred more frequently in primiparous women, 3.9\% (95\% CI 1.7-6\%)than in mixed parity populations, $1.4 \%$ (95\% CI $1.1-1.6 \%)$.
The overall reported OASI rate was $1.4 \%$ (95\% CI 1.2-1.7\%) (Fig. 5).

A geographic representation of the pooled rates of OASI by country (Fig. 6) shows that, similar to episiotomy rates, data were not available for most of LMICs. Philipines had the highest reported rate of $15 \%$ (CI 14-16\%), followed by $10 \%$ (CI 3-17\%) for Pakistan. The lowest pooled reported rate in the meta-analysis was $0.1 \%$ (CI 0.04-0.2\%), in Cambodia. Further meta-analyses estimating the frequency of BTP by mode of delivery were undertaken and are presented in the supplementary material.

\section{Quality Assessment}

The quality assessment revealed poor reporting standards, with only a minority of the studies providing satisfactory

Table 1 Included study characteristics

\begin{tabular}{|c|c|}
\hline \multicolumn{2}{|l|}{ Data overview } \\
\hline Total number of studies & 74 \\
\hline Total number of vaginal births & 334,054 \\
\hline Total number of countries & 42 \\
\hline \multicolumn{2}{|l|}{ Countries' income status ${ }^{\mathrm{a}}$} \\
\hline Low income & 7 \\
\hline Lower-middle income & 19 \\
\hline Upper-middle income & 16 \\
\hline \multicolumn{2}{|l|}{ Study design } \\
\hline Cross-sectional & 28 \\
\hline Cohort & 12 \\
\hline RCT & 15 \\
\hline Other & 19 \\
\hline \multicolumn{2}{|l|}{ Place of birth } \\
\hline Medical facility & 69 \\
\hline Mixed & 3 \\
\hline Home & 2 \\
\hline \multicolumn{2}{|l|}{ Type of delivery ${ }^{\mathrm{a}}$} \\
\hline Assisted delivery & 11 \\
\hline Spontaneous delivery & 14 \\
\hline Mixed & 47 \\
\hline Not stated & 46 \\
\hline \multicolumn{2}{|l|}{ Type of trauma ${ }^{a}$} \\
\hline Episiotomy & 46 \\
\hline 2nd degree & 14 \\
\hline OASIS & 42 \\
\hline Not defined & 16 \\
\hline \multicolumn{2}{|l|}{ Parity $^{\mathrm{a}}$} \\
\hline Primiparous & 31 \\
\hline Multiparous & 3 \\
\hline Mixed & 68 \\
\hline Not stated & 16 \\
\hline
\end{tabular}

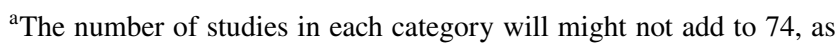
several studies might reported more than one tpe BPT 


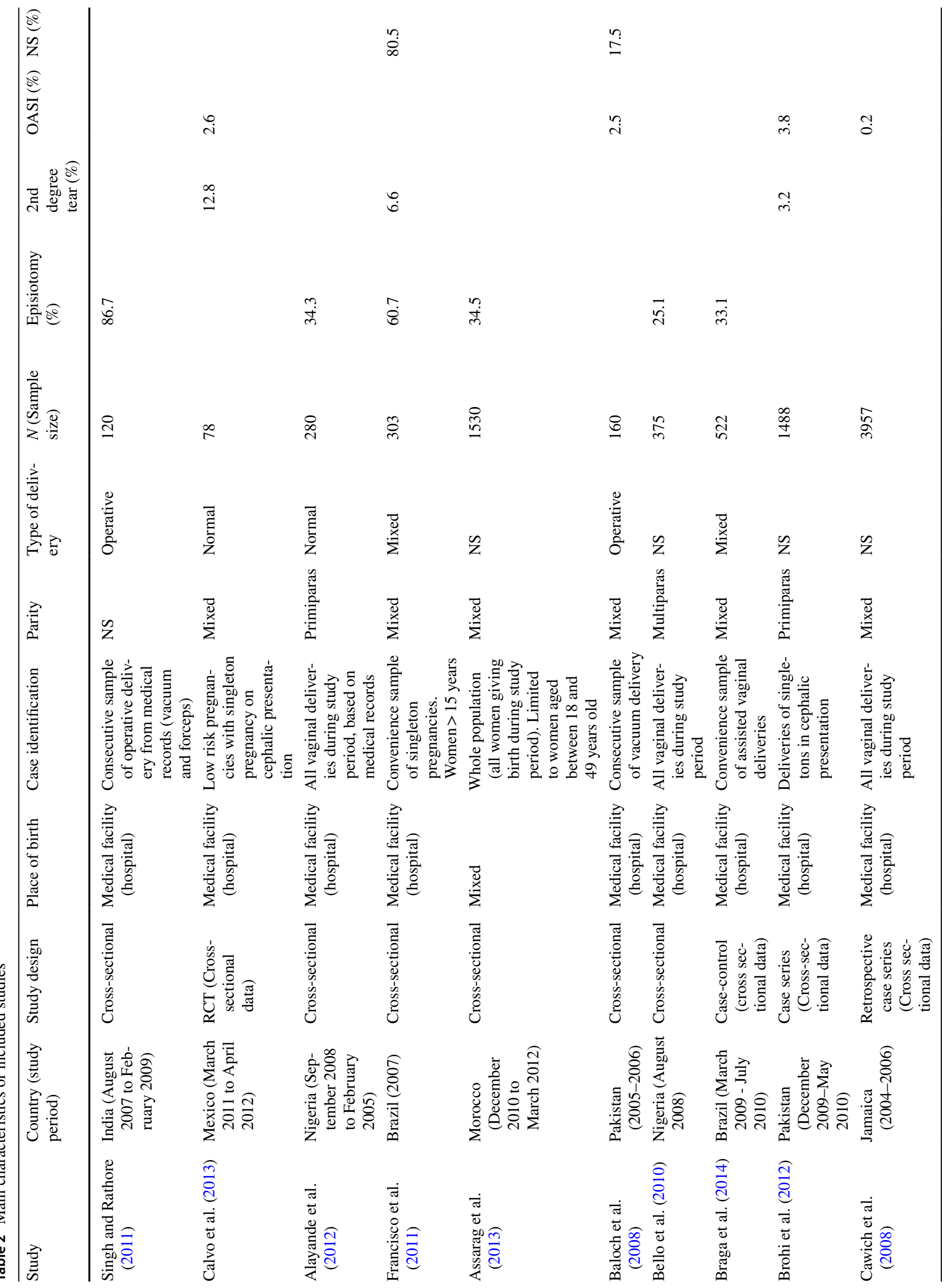




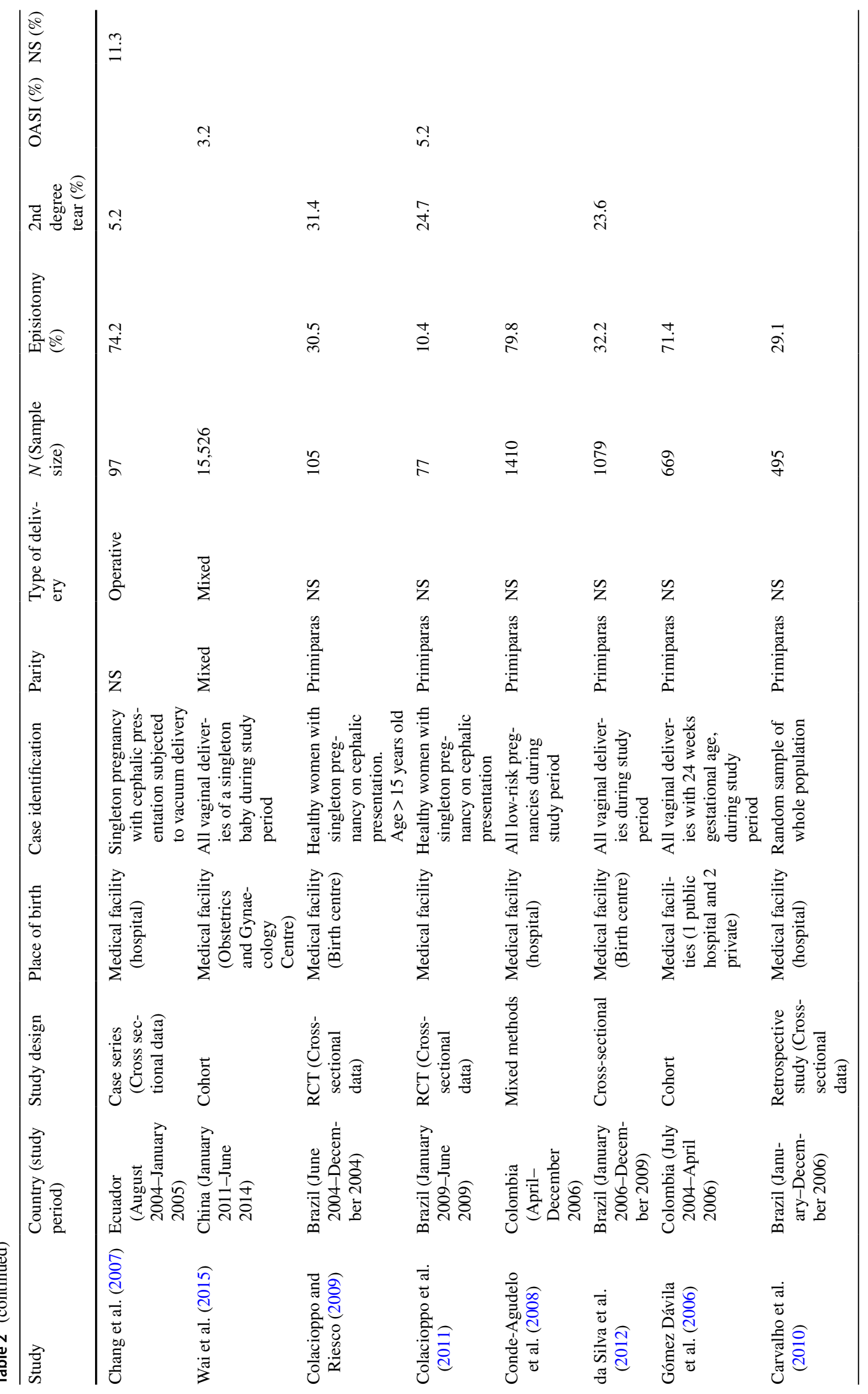




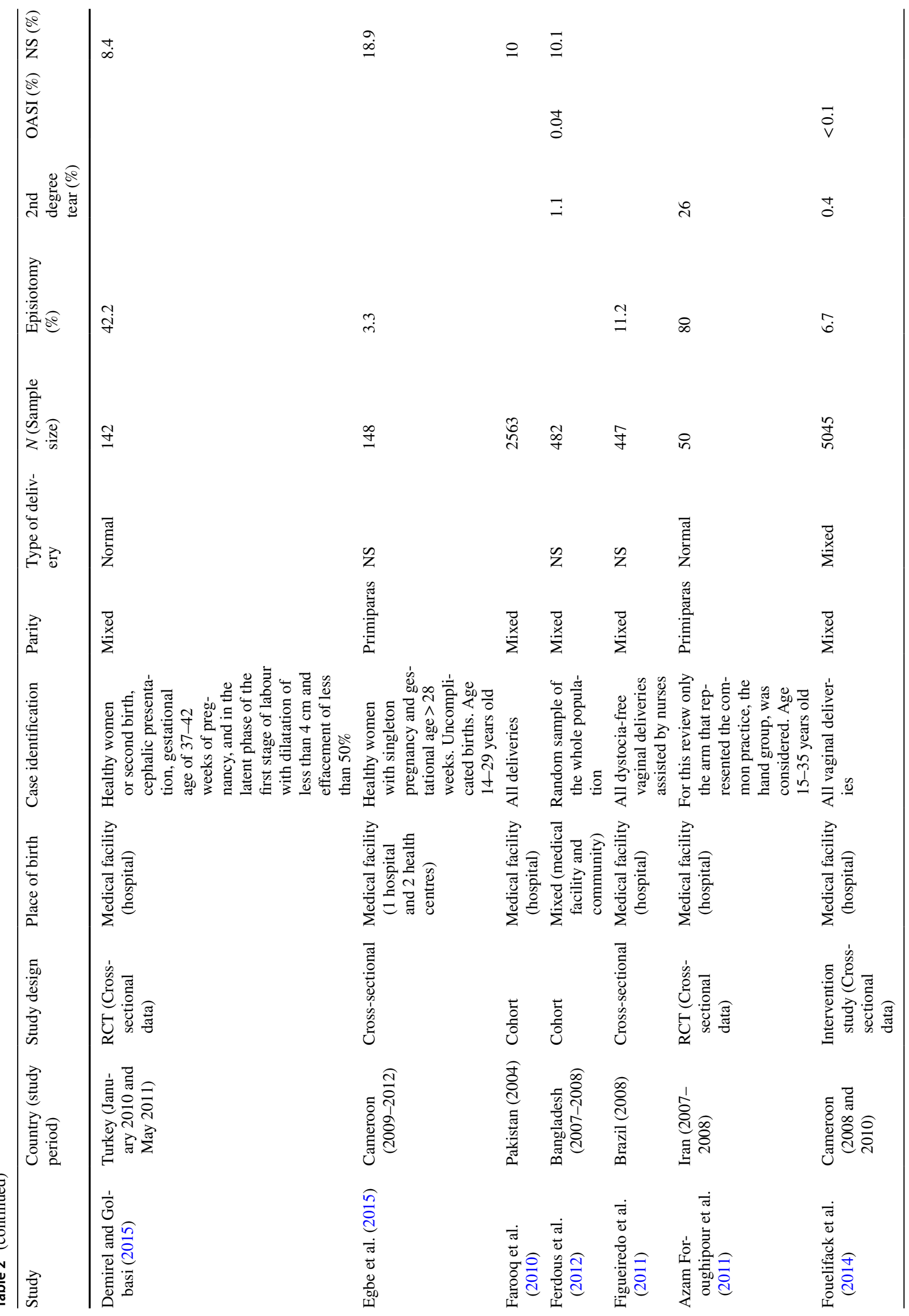




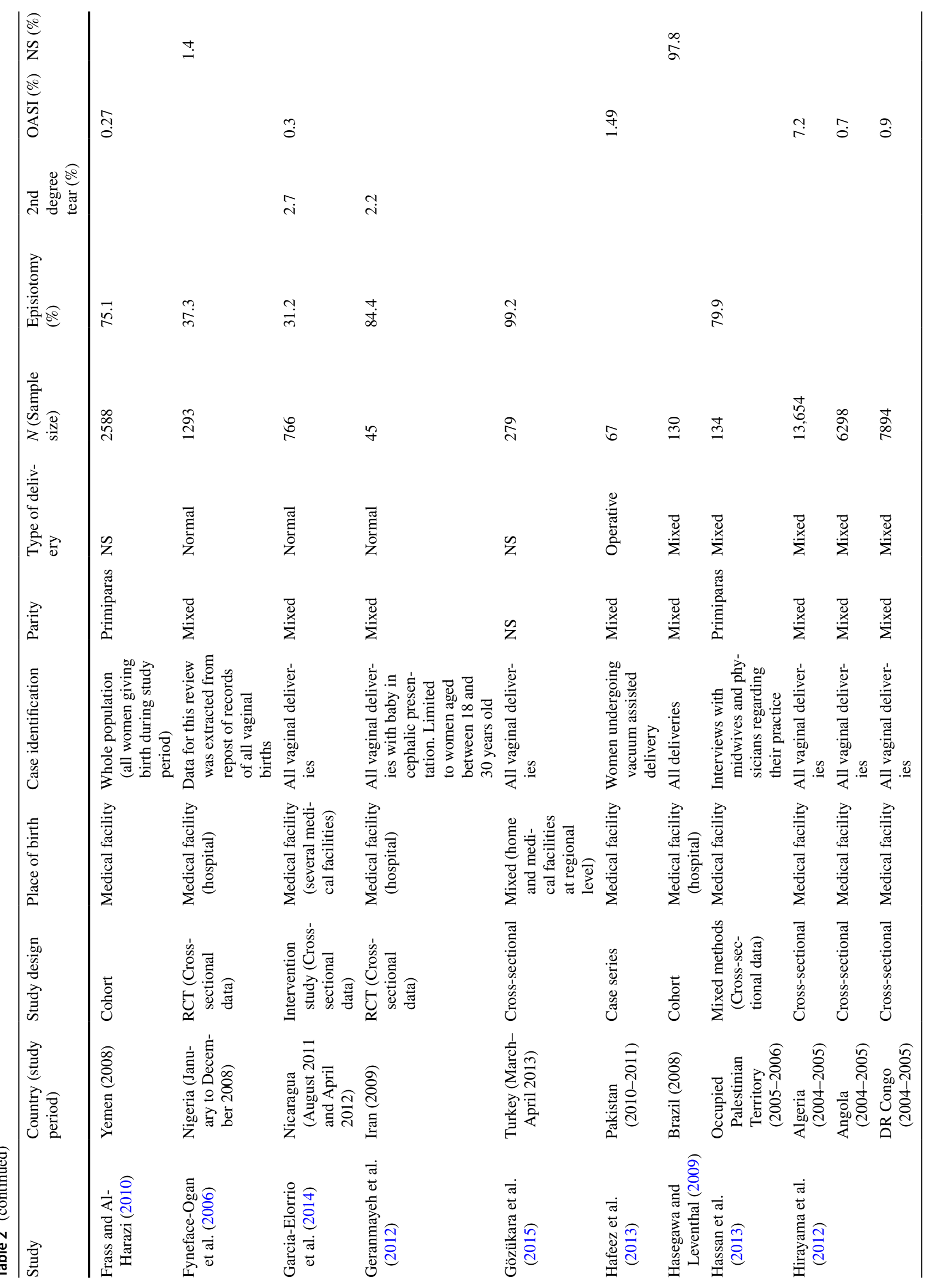




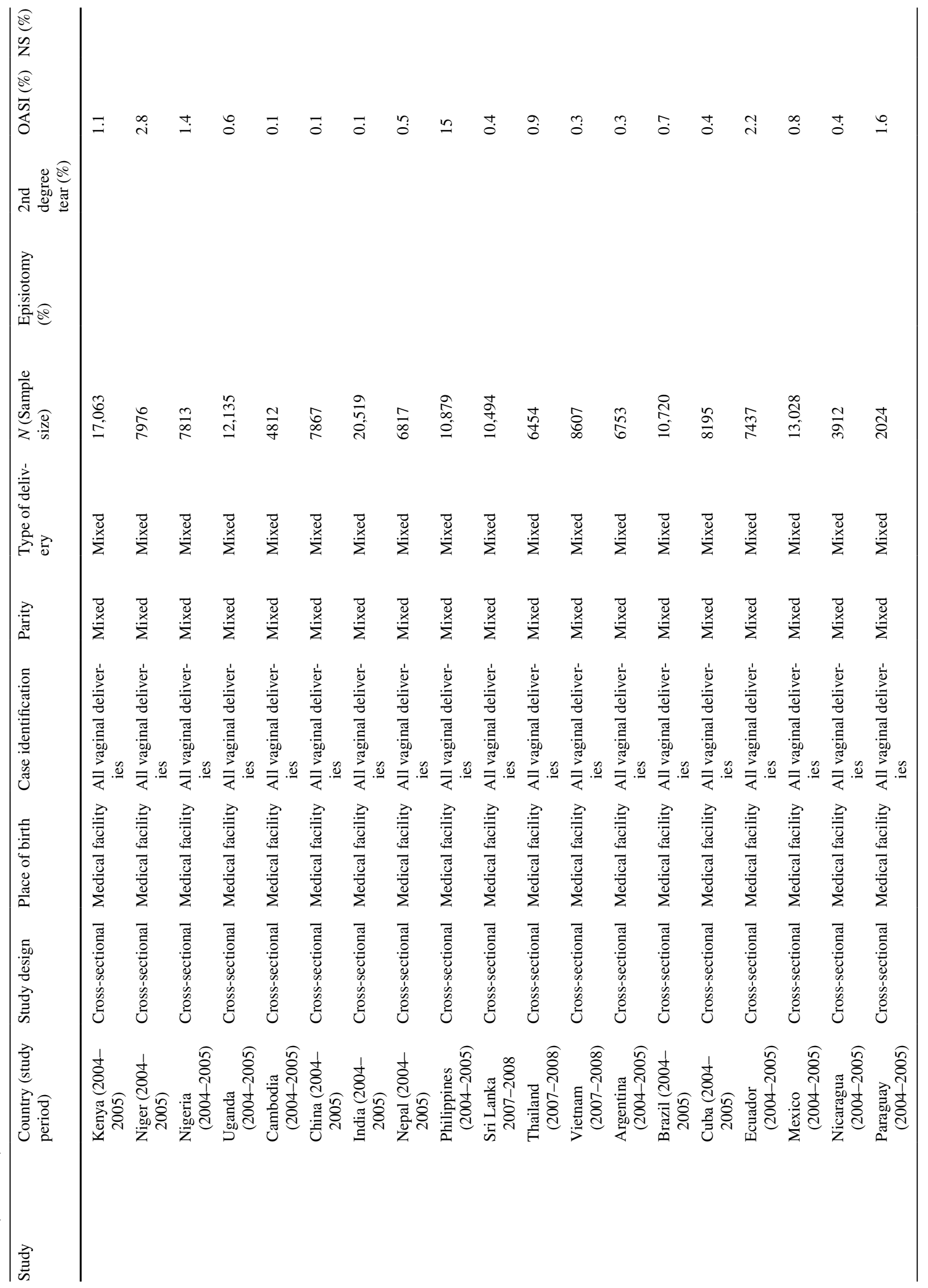




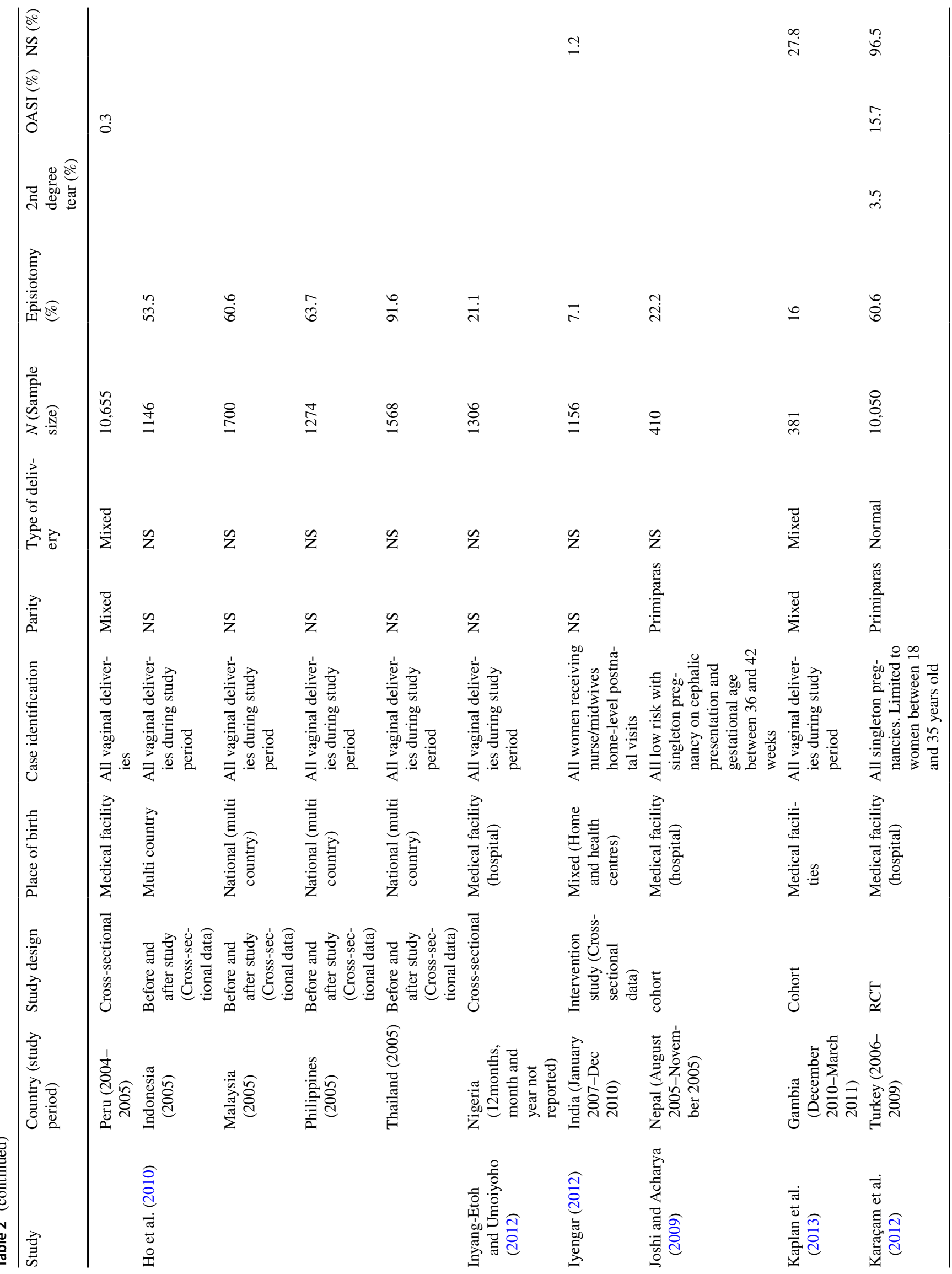




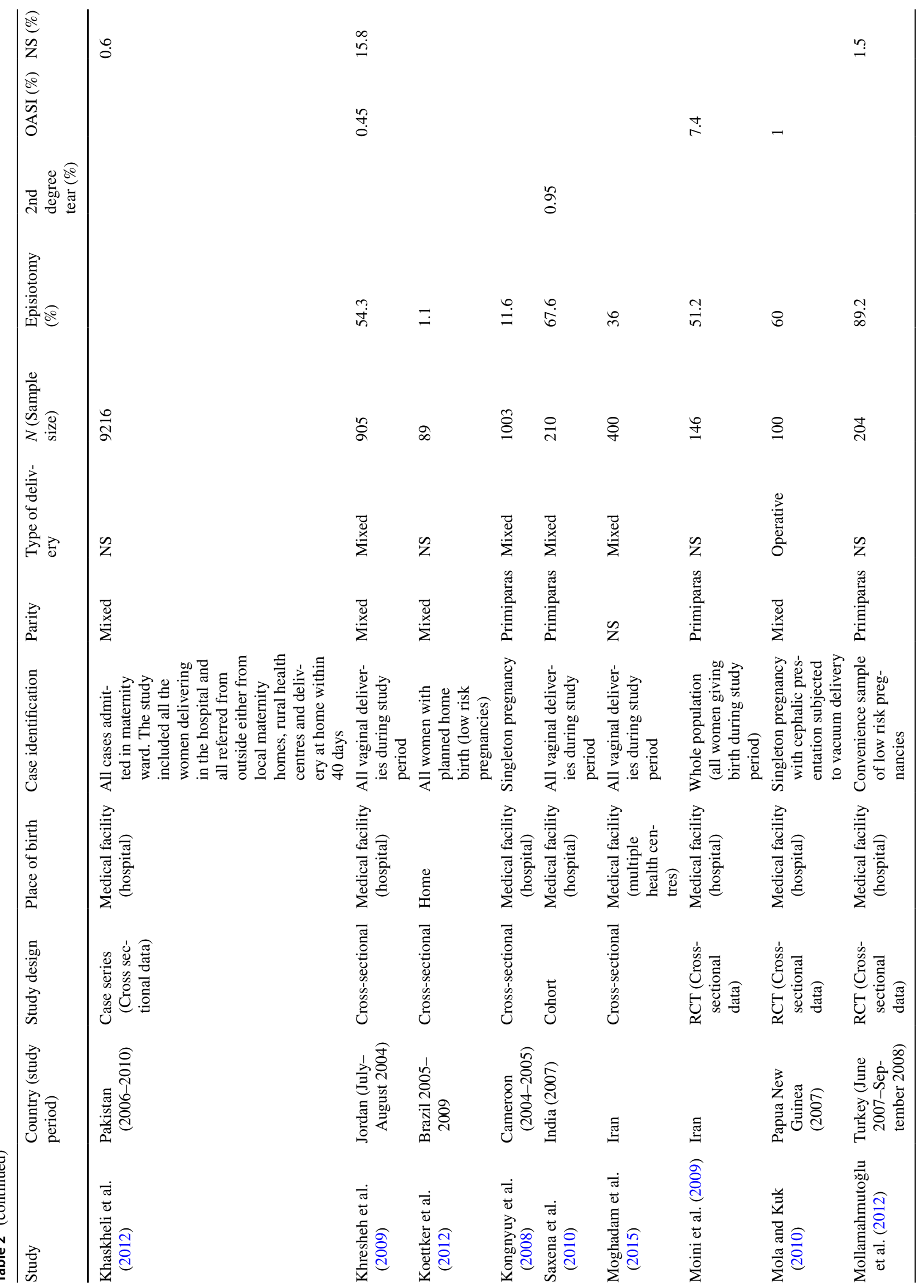




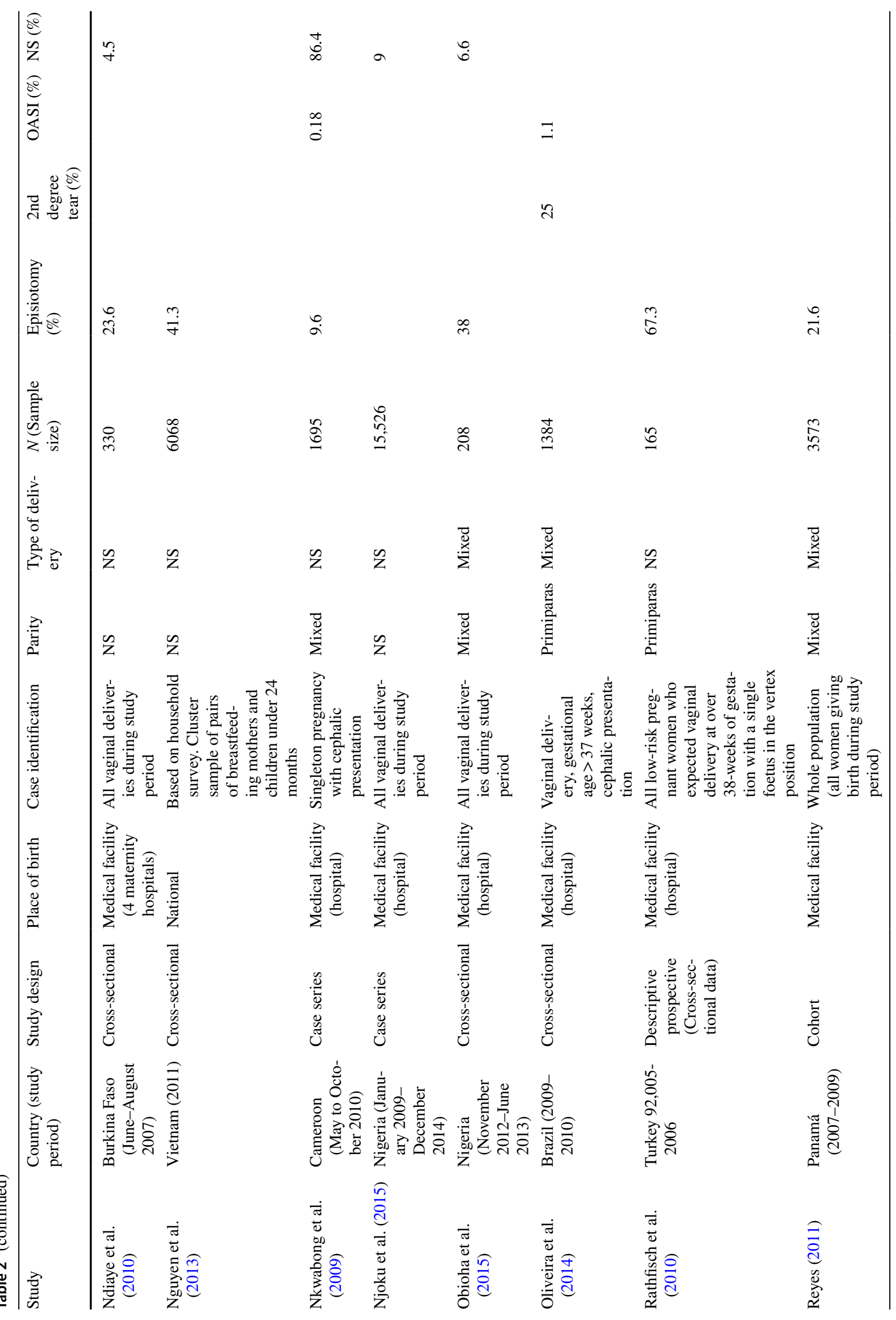




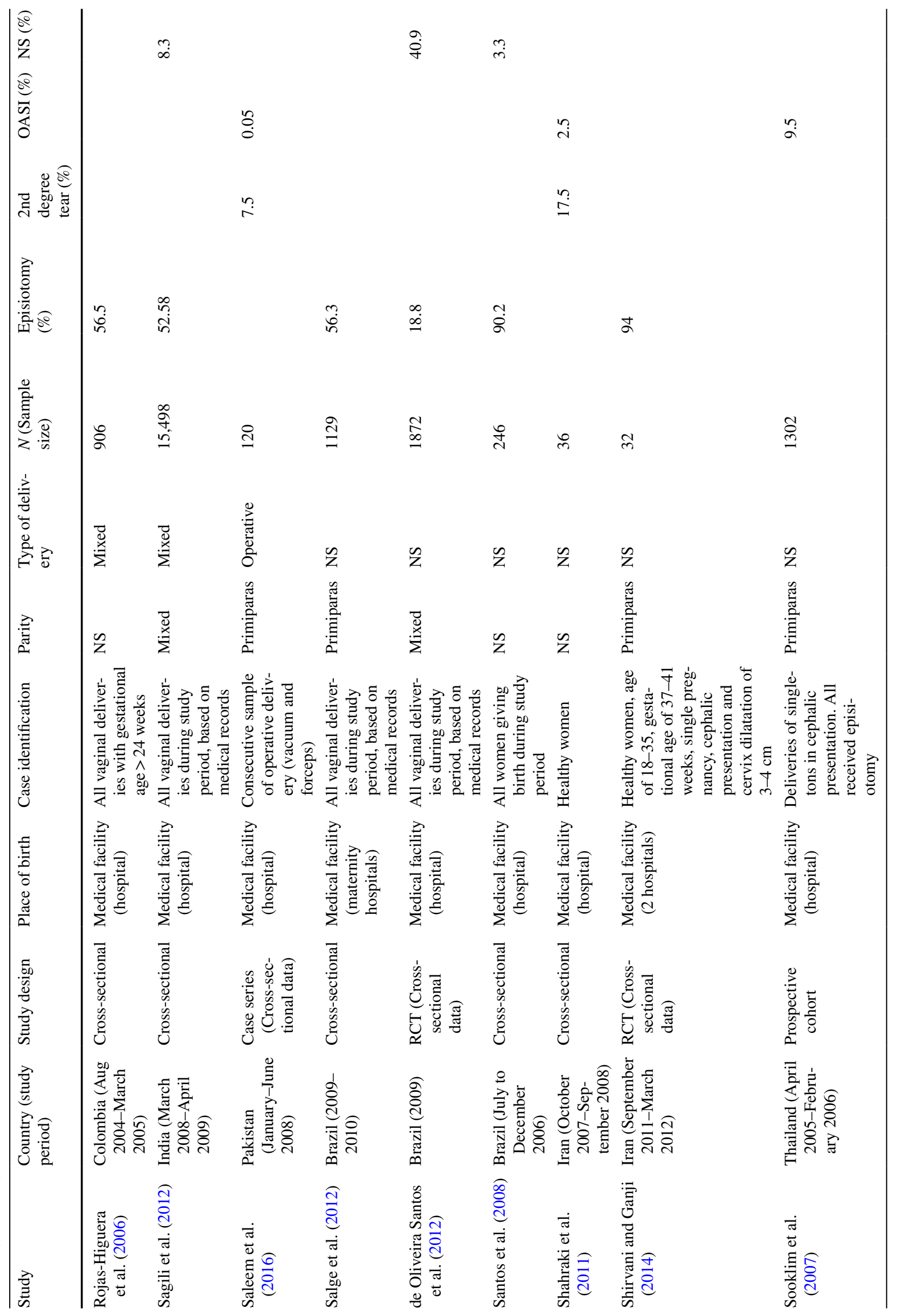


Maternal and Child Health Journal (2019) 23:1048-1070

1061

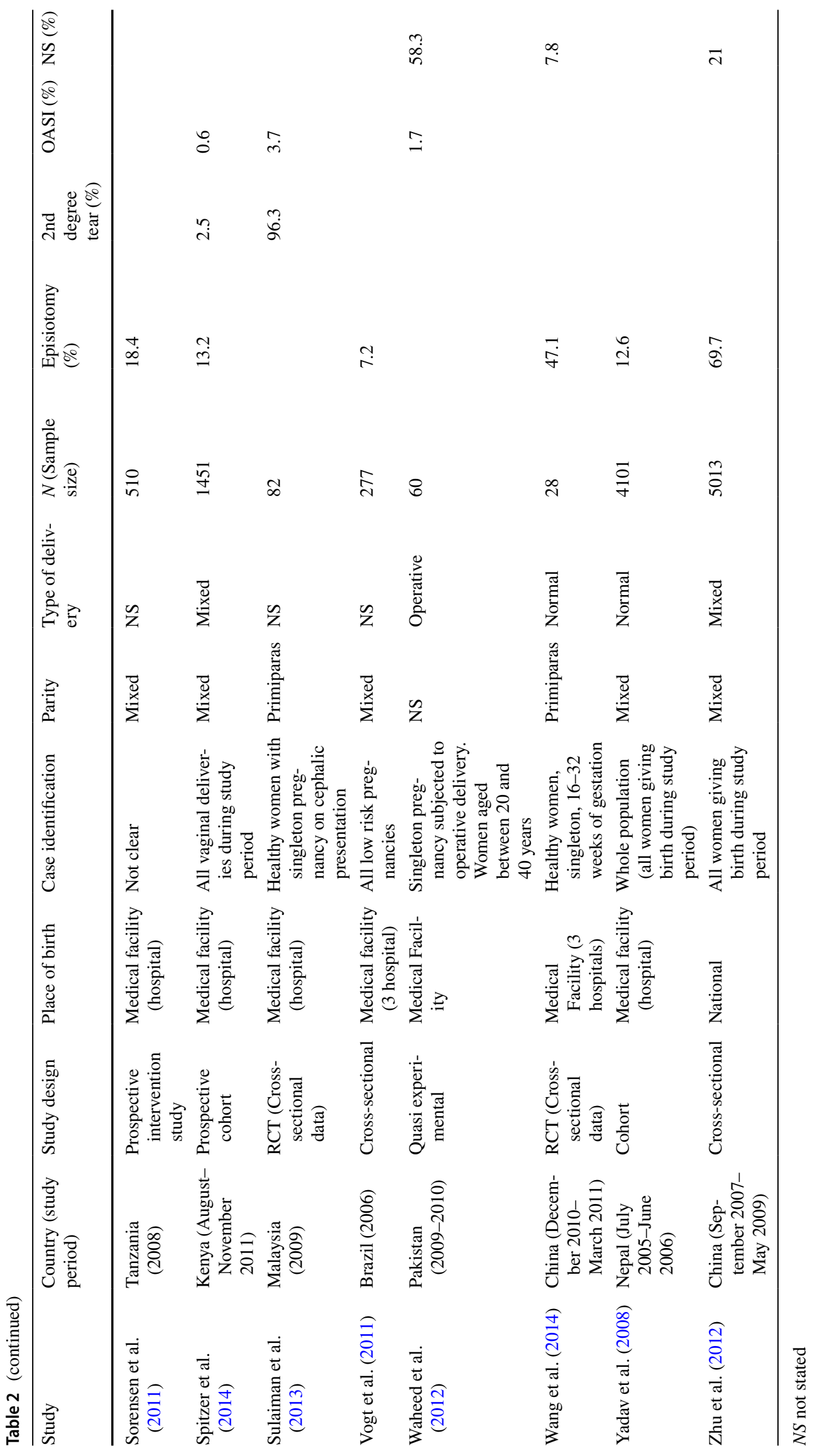

Springer 


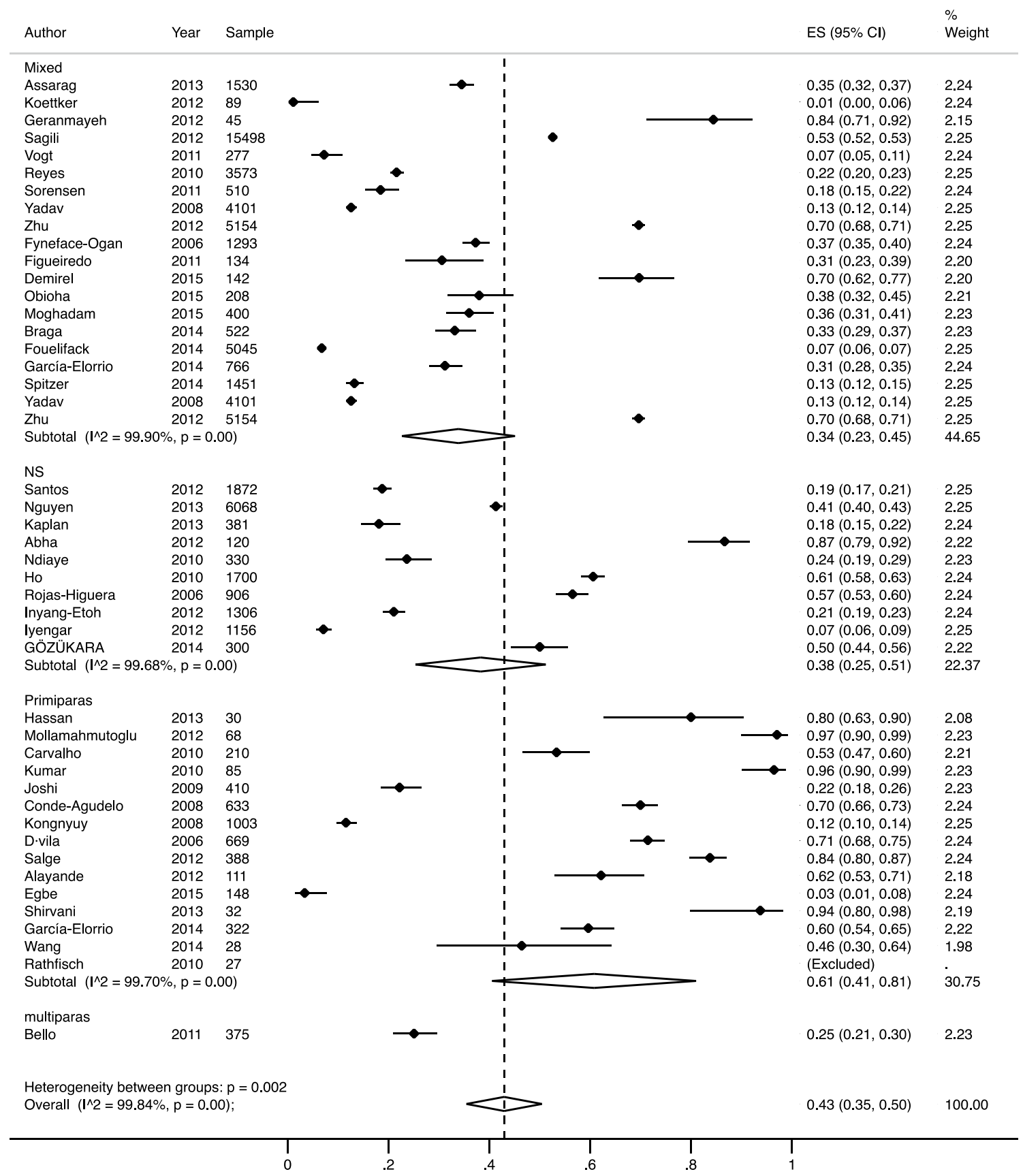

Fig. 2 Forest plot showing results from meta-analysis of the frequency of episiotomy. NS parity not stated in the study

description of how perineal trauma was defined or the characteristics of the studied population (Fig. 5). There was a general effort to avoid selection bias by attempts to include all eligible individuals, and in most studies, the breakdown of the results was reported with the crude estimates rather than summary statistics (Fig. 7).

\section{Discussion}

This systematic review collected data from over 300,000 vaginal births in LMICs to estimate the frequency of episiotomy, second degree tears and OASI. Overall, we estimated that $46 \%$ (95\% CI 35-55\%) of the vaginal births in LMICs were facilitated by an episiotomy, while $23 \%$ (95\% CI 16-29\%) resulted in a spontaneous second degree tear and $1.4 \%$ (95\% CI $1.2-1.7 \%$ ) in OASI. 


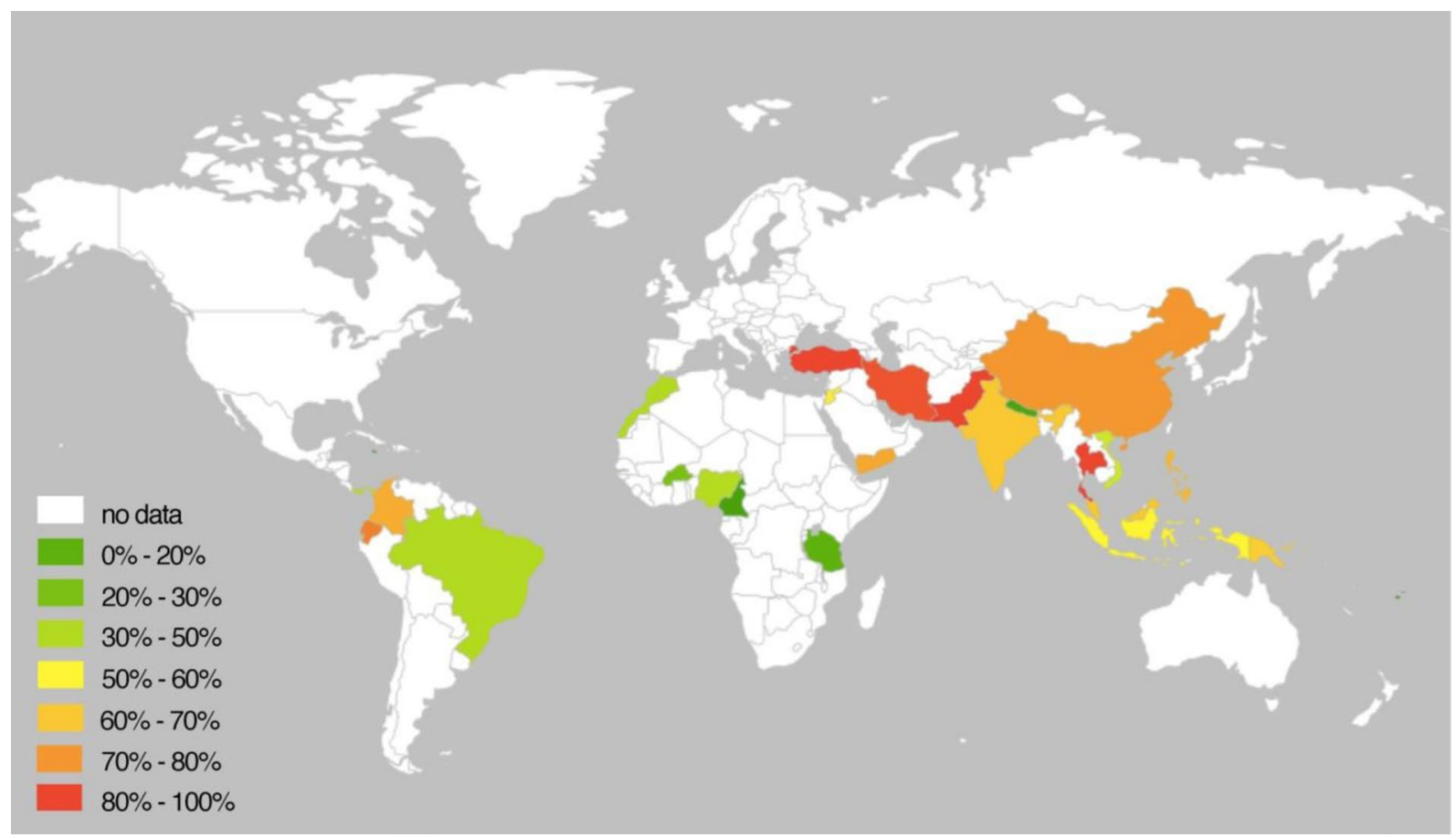

Fig. 3 World map showing the frequency of episiotomy by country

The use of episiotomy is controversial-while there is no evidence to support the use of routine episiotomy to protect from severe perineal tears (Jiang et al. 2017), a recent systematic review shows that women receiving mediolateral episiotomy are less likely to suffer from a severe BPT (Verghese et al. 2016). Selective episiotomy practices are recommended and the WHO states that fewer than $10 \%$ of vaginal births should receive an episiotomy (WHO 1997). Nonetheless, routine use of episiotomy is still common (Lowenstein et al. 2005). In light with these, our results showed that the chance of having an episiotomy is high in births happening in medical facilities, and primiparous women are at a higher risk for all types of BPT. Regarding OASI, our results did not show that women in LMICs are at a higher risk, compared to the average rate of $1.6 \%$ in the Organisation for Economic Co-operation and Development (OECD) countries (OECD 2011). It is likely that the lower rate of OASI we have found in this review is linked to barriers to data collection and underreporting issues in LMICs settings. This is an important issue that needs further investigation since OASI is an important cause of morbidity in LMICs and the incontinence and impaired sexual function resulting from OASI might affect marital relationships, reduce productivity and lead to social isolation in LMIC (WHO \& United Nations Population Fund 2009).

Women in LMICs are often advised to give birth in medical facilities (Goldenberg and McClure 2017; Roro et al. 2014) since these are considered safer environments.
Nonetheless, our findings suggest that routine episiotomy is widely used in some medical practices, raising concerns regarding the quality of the care women receive in these settings. Despite efforts to increase access to medical facilities in LMICs, the proportion of births that take place in the community is high (UNICEF 2008). It has been estimated that 60 million births occur in the community (Darmstadt 2009), where access to health care facilities is compromised for many but there are strongly rooted communitybased health care systems. Nonetheless, the majority of the included studies reported births in medical facilities, denoting a dearth of data on community births. Childbirth happening outside medical facilities, with restricted resources might mean that serious birth-related complications will be more dangerous to the mother and the child (Pasha et al. 2013; Roro et al. 2014). The lack of data on community births was somehow expected. Collection of routine data requires an appropriate structure and trained community workers that poor resource settings lack. Even when such structures are in place, the outcomes of interest are more likely to be maternal and infant mortality related than complications that are perceived as being less severe. Underreporting has been shown to be a problem for outcomes of childbirth in LMICs (Målqvist 2008) but the evidence shows that training community health workers on data collection covering successfully impact the quantity and quality of available data in Ethiopia, Malawi and Mali (Silva et al. 2016). Ideally, data on BPT would be collected alongside 


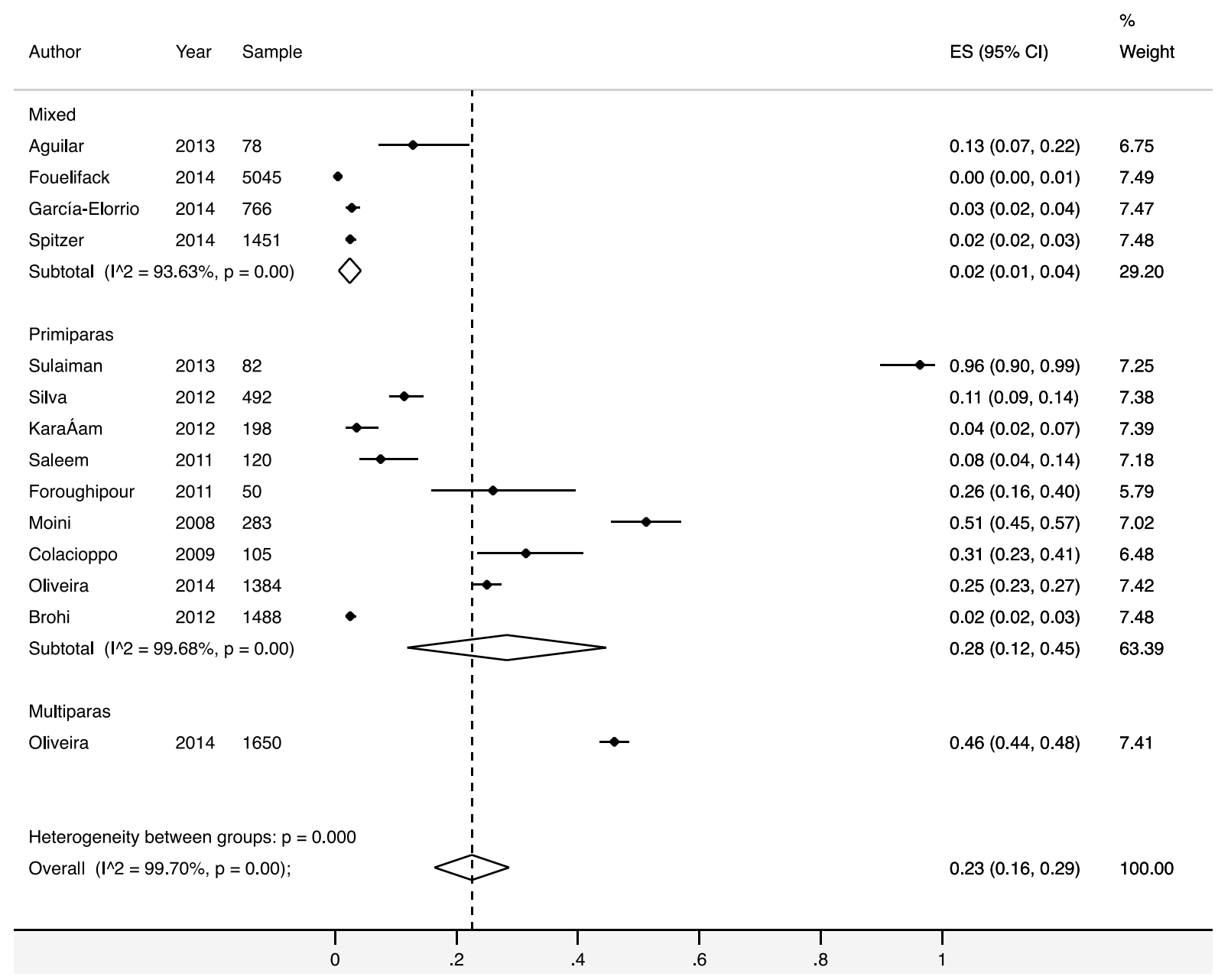

Fig. 4 Forest plot showing results from meta-analysis of the frequency of second degree trauma by parity. NS parity not stated in the study

vital outcomes, in acknowledgement of its high impact on woman's health and wellbeing.

The results of the meta-analyses show high heterogeneity and wide variation within settings, with studies reporting episiotomy rates ranging from $1 \%$ (Koettker et al. 2012) in a Brazilian study of planned home births in low-risk pregnancies, to as high as $99 \%$, as reported by Gözükara et al. in several medical facilities in Thailand (Gözükara et al. 2015). We acknowledge that LMICs is a comprehensive category and a variety of different setting fall indeed into it, so such heterogeneity is not a surprise. Other sources of variation in reported rates could be due to discrepancies in training, local practices and level of experience of accouchers, differences in level of implementation of restrictive episiotomy policies into actual practice and poor reporting practices (Ho et al. 2010).

The main strengths of this systematic review lie in its rigorous methodology and that it provides a comprehensive representation of currently available data on the frequency of BPT in LMICs. A large number of international databases were searched and broad inclusion criteria were applied to allow a wide range of studies to be screened for inclusion, hence providing a thorough picture of BPT in LMICs. However, there were also a number of limitations that are mainly related to the nature of included primary studies that need to be taken into account when interpreting the findings. The scarcity of studies reporting BPT in community births means that the results of this study should not be generalised to those births happening outside medical facilities. While it would be important to ensure appropriate representation of community settings, we acknowledge that data collection from community births might be challenging due to limited resources, difficulty in accessing remote areas, and security concerns in some settings. Additionally, several studies were classified as having high risk of bias, which might have an impact on the accurate estimation of the frequency of BPT. In many cases, the high risk of bias derived from the fact that the study was not designed to investigate BPT, but instead BPT was a secondary outcome. Moreover, we found that the majority of the studies failed to provide an adequate 


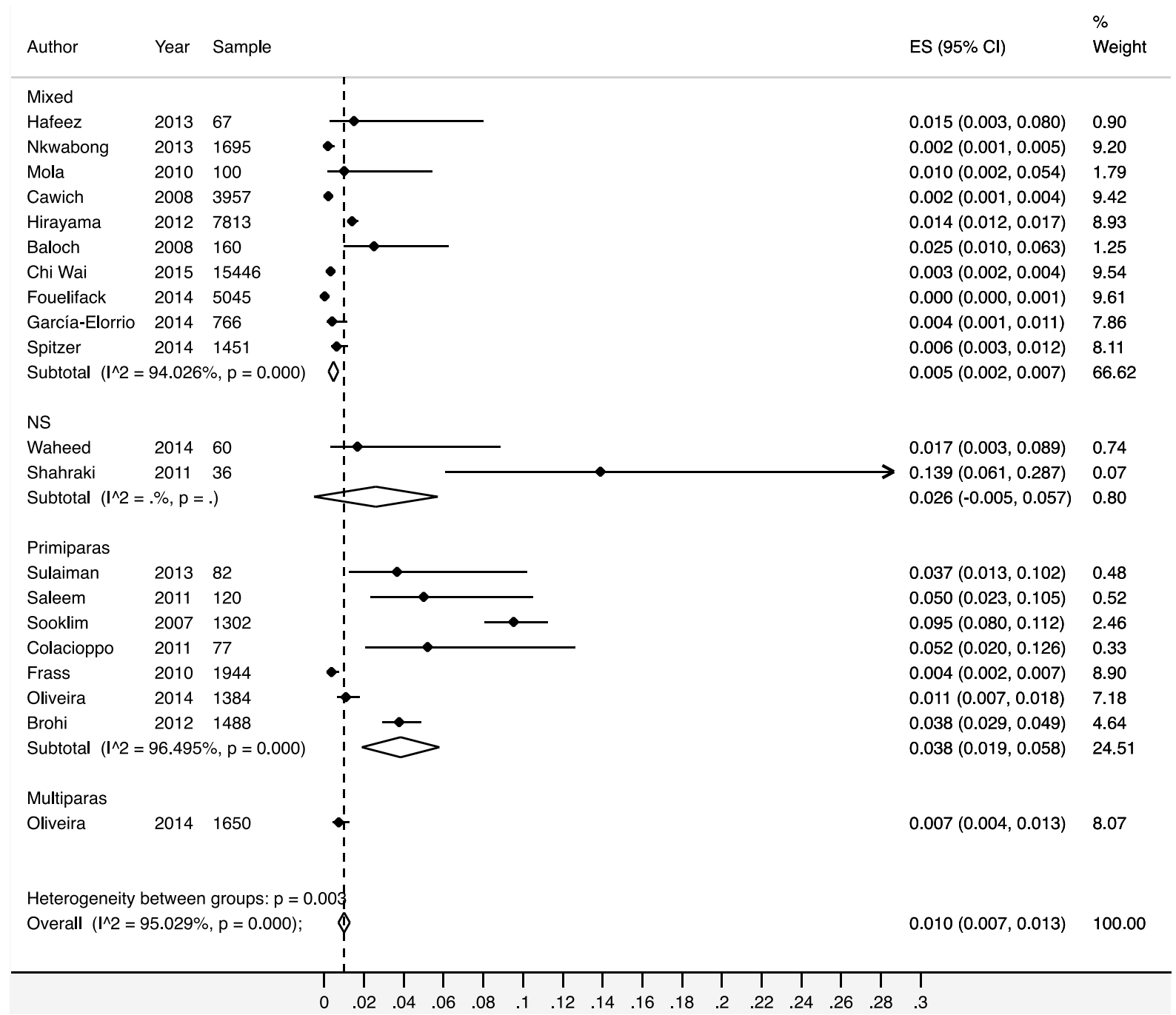

Fig. 5 Forest plot showing results from meta-analysis of the frequency of oasis by parity. NS - parity not stated in the study

definition of BPT. There was also incomplete characterisation of the population under investigation, with most studies providing data on the age of the women only, without adequately describing the population being investigated in terms of important parameters such as the women's sociodemographics characteristics and ethnicity nor birth related characteristics, such as parity and birthweight. These limitations could have contributed to the high level of heterogeneity amongst included studies which is a potential limitation to the external validity of our estimates. The high heterogeneity found in the meta-analyses and the poor quality of the studies means that the pooled estimates of BPT found in this review might be biased. Even so, it is important to report these estimates and highlight the associated issues so that future research can improve reporting practices and more accurate estimates cab be published. Although this review was not able to determine the exact rate of BPT in LMICs, it highlights the importance of improving data collection and reporting of BPT in LMICs. As Silva et al. (2016) found, in the context of mortality rates, it is unlikely that a onesize-fits-all approach will successfully improve reporting of birth-related outcomes. It is our view that future research agendas should aim to improve the quality of reporting and support advances in management of BPT in LMICs by: (1) collaborate with local and national authorities to improve the quality of data available on BPT in medical facilities, and to increase data collection in community setting; (2) disseminate evidence on best practice and support to implementation; (3) in-depth study of setting specific factors, within LMICs that impact care for the perineum, and how management of BPT can be improved. Given the emotional and physical distress BPT has on mothers, BPT should be considered as a core outcome and routine systematic examination of the perineum following childbirth should be performed to reduce misdiagnosis. 


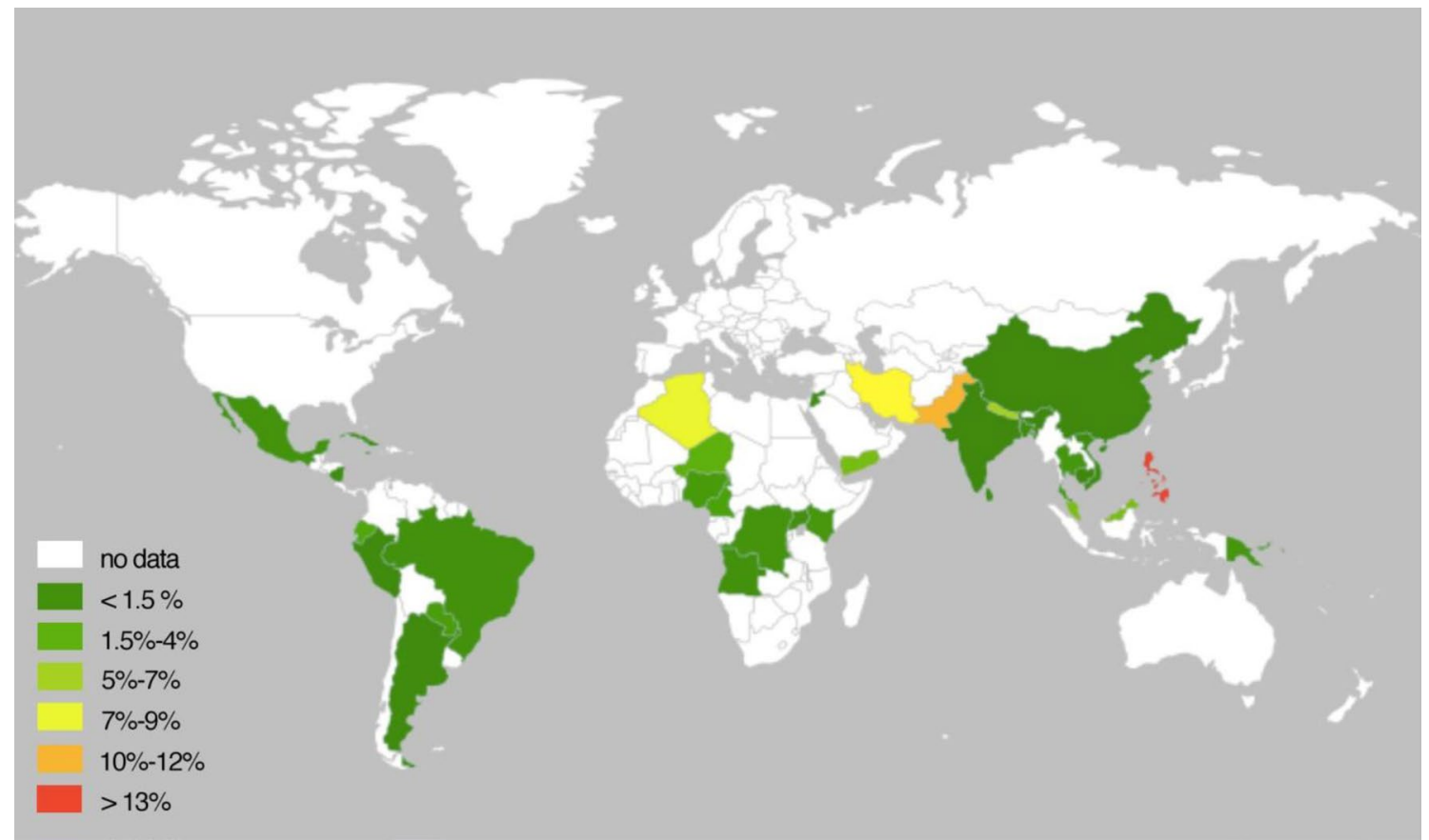

Fig. 6 World map showing the frequency of oasis by country

Describes how perineal trauma was diagnosed and assessed

$$
\begin{array}{r}
\text { Uses a random sample or whole population } \\
\text { Adequate sample size ( }>200 \text { subjects) } \\
\text { Data reported as actual counts (rather than estimates) } \\
\text { Reports response rate and attrition/excluded } \\
\text { Confidence intervals, subgroup analysis } \\
\text { Study subjects described satisfactory }
\end{array}
$$

$$
0
$$

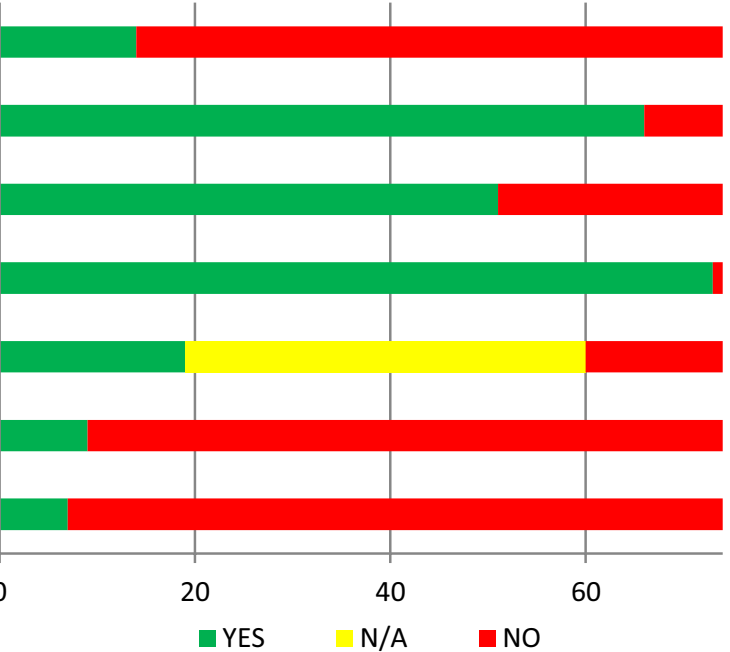

Fig.7 Quality assessement results

\section{Conclusion}

Significant degrees of BPT affect more than $70 \%$ of women having a vaginal birth in LMICs. In this review, we provide insight into how the topic has been approached by researchers, limitations of currently available data and suggestions for improvements. We recommend that there is an urgent need to explore reasons for and devise programmes to reduce the apparent higher rates of episiotomies in LMIC medical facilities. Moreover, it is crucial to unveil BPT rates and outcomes within community based births in LMICs. Both issues are critical in view of their impact on women's short and long term health and the potential impact on a woman's decision regarding place of birth. Finally, the need for better reporting practices and uniformity of classifications is essential to enable appropriate management of such trauma. We believe that these recommendations are essential to improve outcomes for women following BPT particularly in the LMIC low-resource settings with limited facilities 
for managing chronic conditions. We urge policymakers in LMICs to prioritise this area of maternity care for future research, training programmes and quality improvement work.

Acknowledgements We acknowledge that Professor Khaled Ismail provided major contribution to the conception of the project, the development of the protocol, and all drafts of the manuscript.

\section{Compliance with Ethical Standards}

Conflict of interest The authors declare that they have no conflict of interest.

Open Access This article is distributed under the terms of the Creative Commons Attribution 4.0 International License (http://creativeco mmons.org/licenses/by/4.0/), which permits unrestricted use, distribution, and reproduction in any medium, provided you give appropriate credit to the original author(s) and the source, provide a link to the Creative Commons license, and indicate if changes were made.

\section{References}

Aguiar, M., Ismail, I. L., Manaseki-Holland, K. S. (2013). Prevalence and incidence of perineal trauma in low-and middleincome countries (LMICs). Retrieved from the PROSPERO website: http://www.crd.york.ac.uk/PROSPERO/display_recor d.php?ID=CRD42014009036.

Aguilar, O. C., Romero, A. L. F., \& García, V. E. M. (2013). Comparación de resultados obstétricos y perinatales del parto en postura vertical versus supina. Ginecologia y Obstetricia de Mexico, 81, $1-10$.

Alayande, B. T., Amole, I. O., \& Akin, D. (2012). Relative frequency and predictors of episiotomy in Ogbomoso, Nigeria. Internet Journal of Medical Update-EJOURNAL. 7, 2.

Assarag, B., Dubourg, D., Maaroufi, A., Dujardin, B., \& De Brouwere, V. (2013). Maternal postpartum morbidity in Marrakech: What women feel what doctors diagnose? BMC Pregnancy and Childbirth, 13(1), 225.

Azam Foroughipour, F. F., Ghahiri, A., Norbakhsh, V., \& Heidari, T. (2011). The effect of perineal control with hands-on and handpoised methods on perineal trauma and delivery outcome. Journal of research in medical sciences: the official journal of Isfahan University of Medical Sciences, 16(8), 1040.

Baloch, S., Khaskheli, M., Khushk, I. A., \& Sheeba, A. (2008). Frequency of second stage intervention and its outcome in relation with instrumental vaginal delivery versus caesarean section. Journal of Ayub Medical College, Abbottabad: JAMC, 20(1), 87-90.

Bello, F. A., Olayemi, O., Aimakhu, C. O., \& Adekunle, A. O. (2010). Effect of pregnancy and childbirth on sexuality of women in Ibadan, Nigeria. ISRN Obstetrics and Gynecology. https://doi. org/10.5402/2011/856586.

Blondel, B., Alexander, S., Bjarnadóttir, R. I., Gissler, M., LanghoffRoos, J., Novak-Antolič, Ž, \& Zeitlin, J. (2016). Variations in rates of severe perineal tears and episiotomies in 20 European countries: A study based on routine national data in Euro-Peristat Project. Acta obstetricia et gynecologica Scandinavica, 95(7), $746-754$.

Braga, G. C., Clementino, S. T. P., Luz, P. F. N. d., Scavuzzi, A., Neto, N., \& Amorim, M. M. R. (2014). Risk factors for episiotomy:
A case-control study. Revista da Associação Médica Brasileira, $60(5), 465-472$.

Brohi, Z. P., Sadaf, A., Zohra, N., \& Perveen, U. (2012). Frequency and severity of perineal tears in Countess Lady Duffrin Fund Hospital, Hyderabad. JPMA-Journal of the Pakistan Medical Association, 62(8), 803.

Calvo Aguilar, O., Flores Romero, A. L., \& Morales García, V. E. (2013). Comparación de resultados obstétricos y perinatales del parto en postura vertical versus supina. Ginecología y Obstetricia de México. 81(1), 1-10.

Carroli, G., \& Mignini, L. (2009). Episiotomy for vaginal birth. Cochrane Database of Systematic Reviews. 1(1), CD000081.

Carvalho, C. C., Souza, A. S., \& Moraes Filho, O. B. (2010). Prevalence and factors associated with practice of episiotomy at a maternity school in Recife, Pernambuco, Brazil. Revista da Associação Médica Brasileira, 56(3), 333-339.

Cawich, S., Mitchell, D., Martin, A., Brown, H., DaCosta, V., Lewis, T., \& Christie, L. (2008). Management of obstetric anal sphincter injuries at the University Hospital of the West Indies. West Indian Medical Journal, 57(5), 482-485.

Chaabane, K., Trigui, K., Kebaili, S., Louati, D., Ayedi, M., Smaoui, M., \& Gargouri, A. (2013). Detection antenatale de la macrosomie foetale: L'effet des erreurs de diagnostic. Tunisie Medicale, 91(4), 240-242.

Chang, X., Chedraui, P., Ross, M. G., Hidalgo, L., \& Peñafiel, J. (2007). Vacuum assisted delivery in Ecuador for prolonged second stage of labor: Maternal-neonatal outcome. The Journal of Maternal-Fetal \& Neonatal Medicine, 20(5), 381-384.

Colacioppo, P. M., \& Gonzalez Riesco, M. L. (2009). Effectiveness of local anaesthetics with and without vasoconstrictors for perineal repair during spontaneous delivery: Double-blind randomised controlled trial. Midwifery, 25(1), 88-95.

Colacioppo, P. M., Riesco, G., \& Koiffman, M. D. (2011). Use of hyaluronidase to prevent perineal trauma during spontaneous births: A Randomized, placebo-controlled, double-blind, Clinical Trial. Journal of Midwifery \& Women's Health, 56(5), 436-445.

Colacioppo, P. M., \& Riesco, M. L. G. (2009). Effectiveness of local anaesthetics with and without vasoconstrictors for perineal repair during spontaneous delivery: Double-blind randomised controlled trial. Midwifery, 25(1), 88-95.

Conde-Agudelo, A., Rosas-Bermudez, A., \& Gülmezoglu, A. (2008). Evidence-based intrapartum care in Cali, Colombia: A quantitative and qualitative study. BJOG: An International Journal of Obstetrics \& Gynaecology, 115(12), 1547-1556.

da Silva, F., de Oliveira, S. M., Bick, D., Osava, R. H., Tuesta, E. F., \& Riesco, M. L. (2012). Risk factors for birth-related perineal trauma: A cross-sectional study in a birth centre. Journal of clinical nursing, 21(15-16), 2209-2218.

Darmstadt, G. L., Lee, A. C., Cousens, S., Sibley, L., Bhutta, Z. A., Donnay, F., \& Baqui, A. (2009). 60 million non-facility births: Who can deliver in community settings to reduce intrapartumrelated deaths? International Journal of Gynecology \& Obstetrics, 107(Supplement 1), S89-112.

de Oliveira Santos, J., de Oliveira, S. M. J. V., Nobre, M. R. C., Aranha, A. C. C., \& Alvarenga, M. B. (2012). A randomised clinical trial of the effect of low-level laser therapy for perineal pain and healing after episiotomy: A pilot study. Midwifery, 28(5), e653-e659.

Demirel, G., \& Golbasi, Z. (2015). Effect of perineal massage on the rate of episiotomy and perineal tearing. International Journal of Gynecology \& Obstetrics, 131(2), 183-186.

Egbe, T. O., Omeichu, A., Halle-Ekane, G. E., Tchente, C. N., Egbe, E.-N., \& Oury, J.-F. (2015). Prevalence and outcome of teenage hospital births at the buea health district, South West Region, Cameroon. Reproductive health, 12(1), 118.

Elharmeel, S., Chaudhary, Y., Tan, S., Scheermeyer, E., Hanafy, A., \& van Driel, M. L. (2011). Surgical repair of spontaneous 
perineal tears that occur during childbirth versus no intervention. Cochrane Database of Systematic Reviviews. 8, CD008534.

Farooq, S., Farook, S. M., \& Abbassi, R. M. (2010). Pattern of perineal tears during vaginal delivery at a public sector University Hospital of Sindh. Pakistan Journal of medical sciences online, 26(4), 856-859.

Ferdous, J., Ahmed, A., Dasgupta, S., Jahan, M., Huda, F., Ronsmans, C., \& Chowdhury, M. (2012). Occurrence and determinants of postpartum maternal morbidities and disabilities among women in Matlab, Bangladesh. Journal of Health, Population, and Nutrition, 30(2), 143.

Figueiredo, G. S., Santos, T. T. R., Reis, C. S. C., Mouta, R. J. O., Progianti, J. M., \& Vargens, O. M. (2011). Ocorrência de episiotomia em partos acompanhados por enfermeiros obstetras em ambiente hospitalar. Revista Enfermagem UERJ, 19, 181-185.

Fouelifack, F. Y., Tameh, T. Y., Mbong, E. N., Nana, P. N., Fouedjio, J. H., Fouogue, J. T., \& Mbu, R. E. (2014). Outcome of deliveries among adolescent girls at the Yaoundé central hospital. BMC Pregnancy and Childbirth, 14(1), 102.

Francisco, A. A., de Oliveira, S. M. J. V., da Silva, F. M. B., Bick, D., \& Riesco, M. L. G. (2011). Women's experiences of perineal pain during the immediate postnatal period: A cross-sectional study in Brazil. Midwifery, 27(6), e254-e259.

Frass, K. A., \& Al-Harazi, A. H. (2010). Episiotomy is still performed routinely in Yemeni women. Saudi Medical Journal, 31(7), 764-767.

Fyneface-Ogan, S., Mato, C. N., \& Enyindah, C. E. (2006). Postpartum perineal pain in primiparous women: a comparison of two local anaesthetic agents. Nigerian Journal of Medicine, 15(1), 77-80.

Garcia-Elorrio, E., Aleman, A., Cafferata, M. L., Colomar, M., Tomasso, G., Lacayo, Y., \& Althabe, F. (2014). A multifaceted intervention to increase prophylactic oxytocin use during the third stage of labor and to reduce routine episiotomies in Nicaragua. International Journal of Gynaecology and Obstetrics, 127(1), 31-34. https://doi.org/10.1016/j.ijgo.2014.04.019.

Geranmayeh, M., Habibabadi, Z. R., Fallahkish, B., Farahani, M. A., Khakbazan, Z., \& Mehran, A. (2012). Reducing perineal trauma through perineal massage with vaseline in second stage of labor. Archives of Gynecology and Obstetrics, 285(1), 77-81.

Goldenberg, R. L., \& McClure, E. M. (2017). Improving Birth Outcomes in Low- and Middle-Income Countries. New England Journal of Medicine, 377(24), 2387-2388. https://doi. org/10.1056/NEJMe1713831.

Gómez Dávila, J. G., Londoño Cardona, J. G., \& Monterrosa, E. d. (2006). Frecuencia de uso de prácticas médicas basadas en la evidencia en el cuidado del parto en hospitales de la ciudad de Medellín. Años 2004 y 2005. Iatreia. 19, 1.

Gözükara, F., Koruk, I., \& Kara, B. (2015). Urinary incontinence among women registered with a family health center in the Southeastern Anatolia Region and the factors affecting its prevalence. Turkish Journal of Medical Sciences, 45(4), 931-939.

Gülmezoglu, A. M., Say, L., Betrán, A. P., Villar, J., \& Piaggio, G. (2004). WHO systematic review of maternal mortality and morbidity: Methodological issues and challenges. BMC Medical Research Methodology, 4(1), 16.

Hafeez, M., Badar, N., \& Yasin, A. (2013). Indications and risks of vacuum assisted deliveries. Journal of International Medical Sciences Academy, 26(4), 213-214.

Hasegawa, J., \& Leventhal, L. C. (2009). Pharmacological and non pharmacological treatmente for relief of perineal pain after vaginal delivery. Einstein (São Paulo), 7(2), 194-200.

Hassan, S. J., Sundby, J., Husseini, A., \& Bjertness, E. (2013). Translating evidence into practice in childbirth: A case from the occupied palestinian territory. Women and Birth, 26(2), e82-e89.

Hirayama, F., Koyanagi, A., Mori, R., Zhang, J., Souza, J., \& Gülmezoglu, A. (2012). Prevalence and risk factors for third-and fourth-degree perineal lacerations during vaginal delivery: A multi-country study. BJOG, 119(3), 340-347.

Ho, J. J., Pattanittum, P., Japaraj, R. P., Turner, T., Swadpanich, U., \& Crowther, C. A. (2010). Influence of training in the use and generation of evidence on episiotomy practice and perineal trauma. International Journal of Gynecology \& Obstetrics, 111(1), $13-18$.

Huebner, M., Gramlich, N. K., Rothmund, R., Nappi, L., Abele, H., \& Becker, S. (2013). Fecal incontinence after obstetric anal sphincter injuries. International Journal of Gynecology \& Obstetrics, 121(1), 74-77. https://doi.org/10.1016/j.ijgo.2012.10.023. doi.

Inyang-Etoh, E., \& Umoiyoho, A. (2012). The practice of episiotomy in a university teaching hospital in Nigeria: How satisfactory? International Journal of Medicine and Biomedical Research, $1(1), 68-72$.

Islam, M. (2007). The safe motherhood initiative and beyond. Bulletin of the World Health Organization., 85(10), 735.

Iyengar, K. (2012). Early postpartum maternal morbidity among rural women of Rajasthan, India: A community-based study. Journal of Health, Population, and Nutrition, 30(2), 213.

Jiang, H., Qian, X., Carroli, G., \& Garner, P. (2017). Selective versus routine use of episiotomy for vaginal birth. The Cochrane Database of Systematic Reviews. https://doi.org/10.1002/14651858.

Joshi, A., \& Acharya, R. (2009). Perineal outcome after restrictive use of episiotomy in primi-gravidas. JNMA, 48(176), 269-272.

Kaplan, A., Forbes, M., Bonhoure, I., Utzet, M., Martín, M., Manneh, M., \& Ceesay, H. (2013). Female genital mutilation/cutting in The Gambia: Long-term health consequences and complications during delivery and for the newborn. International Journal of Women's Health, 5, 323-331. https://doi.org/10.2147/IJWH. S42064.

Karaçam, Z., Ekmen, H., \& Çalişir, H. (2012). The use of perineal massage in the second stage of labor and follow-up of postpartum perineal outcomes. Health Care for Women International, 33(8), 697-718.

Kettle, C., Dowswell, T., \& Ismail, K. M. (2012). Continuous and interrupted suturing techniques for repair of episiotomy or seconddegree tears. The Cochrane Database of Systematic Reviews. https://doi.org/10.1002/14651858.

Kettle, C., \& Tohill, S. (2008). Perineal care. Clinical Evidence. 2008, 1401.

Khaskheli, M., Baloch, S., \& Baloch, A. S. (2012). Obstetrical trauma to the genital tract following vaginal delivery. Journal of the College of Physicians and Surgeons Pakistan, 22(2), 95-97.

Khresheh, R., Homer, C., \& Barclay, L. (2009). A comparison of labour and birth outcomes in Jordan with WHO guidelines: A descriptive study using a new birth record. Midwifery, 25(6), e11-e18.

Koettker, J. G., Brüggemann, O. M., Dufloth, R. M., Knobel, R., \& Monticelli, M. (2012). Outcomes of planned home birth assisted by nurses, from 2005 to 2009, in Florianópolis, Brazil. Revista de saude publica, 46(4), 747-750.

Kongnyuy, E. J., Nana, P. N., Fomulu, N., Wiysonge, S. C., Kouam, L., $\&$ Doh, A. S. (2008). Adverse perinatal outcomes of adolescent pregnancies in Cameroon. Maternal and Child Health Journal, 12(2), 149-154.

Loney, P. L., Chambers, L. W., Bennett, K. J., Roberts, J. G., \& Stratford, P. W. (1998). Critical appraisal of the health research literature: Prevalence or incidence of a health problem. Chronic Diseases in Canada, 19(4), 170-176.

Lowenstein, L., Drugan, A., Gonen, R., Itskovitz-Eldor, J., Bardicef, M., \& Jakobi, P. (2005). Episiotomy: beliefs, practice and the impact of educational intervention. European Jouranl of Obstetrics Gynecology and Reproductive Biology, 123(2), 179-182. https://doi.org/10.1016/j.ejogrb.2005.04.006.

Målqvist, M., Eriksson, L., Nga, N. T., Fagerland, L. I., Hoa, D. P., Wallin, L., \& Persson, L. (2008). Unreported births and deaths, 
a severe obstacle for improved neonatal survival in low-income countries: A population based study. BMC International Health and Human Rights, 8(1), 4.

Moghadam, M. F., Shamsi, A., \& Moro, F. H. (2015). The prevalence of post-traumatic stress disorder among women with normal vaginal delivery in Zahedan city. Archives of Psychiatry and Psychotherapy, 1, 15-19.

Moher, D., Liberati, A., Tetzlaff, J., \& Altman, D. G. (2010). Preferred reporting items for systematic reviews and meta-analyses: the PRISMA statement. International Journal of Surgery, 8(5), 336-341.

Moini, A., Yari, R. E. A., \& Eslami, B. (2009). Episiotomy and thirdand fourth-degree perineal tears in primiparous Iranian women. International Journal of Gynecology \& Obstetrics, 104(3), 241-242.

Mola, G. D., \& Kuk, J. M. (2010). A randomised controlled trial of two instruments for vacuum-assisted delivery (Vacca Re-Usable OmniCup and the Bird anterior and posterior cups) to compare failure rates, safety and use effectiveness. Australian and New Zealand Journal of Obstetrics and Gynaecology, 50(3), 246-252.

Mollamahmutoğlu, L., Moraloğlu, Ö, Özyer, Ş, Su, F. A., Karayalçın, R., Hançerlioğlu, N., \& Dilmen, U. (2012). The effects of immersion in water on labor, birth and newborn and comparison with epidural analgesia and conventional vaginal delivery. Journal of the Turkish German Gynecological Association, 13(1), 45.

Mota, R. L. (2017). Female urinary incontinence and sexuality. International Brazilian Journal of Urology, 43(1), 20-28.

Ndiaye, P., Diongue, M., Faye, A., Ouedraogo, D., \& Dia, T., A (2010). [Female genital mutilation and complications in childbirth in the province of Gourma (Burkina Faso)]. Sante Publique, 22(5), 563-570.

Nguyen, P. H., Keithly, S. C., Nguyen, N. T., Nguyen, T. T., Tran, L. M., \& Hajeebhoy, N. (2013). Prelacteal feeding practices in Vietnam: Challenges and associated factors. BMC Public Health, 13(1), 932.

Njoku, C., Emechebe, C., Iklaki, C., \& Nnorom, F. (2015). The pattern and maternal outcome of lower genital tract injuries among women with vaginal deliveries in Calabar. A Niger delta state of Nigeria, 2015, 190-195.

Nkwabong, E., Kouam, L., Orock, G., Ekono, M., Takang, W., \& Mve, K. (2009). Study of perineal tears during delivery of singletons in cephalic presentation. Tropical Journal of Obstetrics and Gynaecology, 26(2), 128-131.

Nyaga, V. N., Arbyn, M., \& Aerts, M. (2014). METAPROP: Stata module to perform fixed and random effects meta-analysis of proportions. Statistical Software Components.

Obioha, K. C., Ugwu, E. O., Obi, S. N., Dim, C. C., \& Oguanuo, T. C. (2015). Prevalence and predictors of urinary/anal incontinence after vaginal delivery: prospective study of Nigerian women. International urogynecology journal, 26(9), 1347-1354.

OECD (2011). Health at a Glance 2011: OECD Indicators. Paris: OECD Publishing. https://doi.org/10.1787/health_glanc e-2015-en.

Oliveira, L. S., Brito, L. G. O., Quintana, S. M., Duarte, G., \& Marcolin, A. C. (2014). Perineal trauma after vaginal delivery in healthy pregnant women. Sao Paulo Medical Journal, 132(4), 231-238.

Pasha, O., McClure, E. M., Wright, L. L., Saleem, S., Goudar, S. S., Chomba, E., \& Althabe, F. (2013). A combined community-and facility-based approach to improve pregnancy outcomes in lowresource settings: A Global Network cluster randomized trial. BMC Medicine, 11(1), 215.

Poen, A. C., Felt-Bersma, R. J., Strijers, R. L., Dekker, G. A., Cuesta, M. A., \& Meuwissen, S. G. (1998). Third-degree obstetric perineal tear: Long-term clinical and functional results after primary repair. British Journal of Surgery, 85(10), 1433-1438.
Rathfisch, G., Dikencik, B. K., Beji, K., Comert, N., Tekirdag, N., \& Kadioglu, A. (2010). Effects of perineal trauma on postpartum sexual function. Journal of Advanced Nursing, 66(12), $2640-2649$.

Reyes, O. (2011). Riesgo de hemorragia posparto en la paciente gran multípara: Estudio retrospectivo observacional. Clínica e Investigación en Ginecología y Obstetricia, 38(5), 169-172.

Rojas-Higuera, R., Londoño-Cardona, J. G., \& Arango-Gómez, F. (2006). Prácticas clínicas en el cuidado de gestantes y recién nacidos en algunos hospitales de Bogotá, Colombia. Revista de Salud Pública, 8, 223-234.

Roro, M. A., Hassen, E. M., Lemma, A. M., Gebreyesus, S. H., \& Afework, M. F. (2014). Why do women not deliver in health facilities: A qualitative study of the community perspectives in south central Ethiopia? BMC Research Notes, 7, 556. https://doi. org/10.1186/1756-0500-7-556.

Royal College of Midwives (2012). Evidence based guidelines for midwifery-led care in labour: Supporting women in labour. London: Royal College of Midwives

Sagili, H., Pramya, N., Prabhu, K., Mascarenhas, M., \& Rani, P. R. (2012). Are teenage pregnancies at high risk? A comparison study in a developing country. Archives of Gynecology and Obstetrics, 285(3), 573-577.

Saleem, S. T., Saeed, I., \& Baig, M. I. (2016). Short term maternal and neonatal outcomes in operative vaginal deliveries in singleton term pregnancies. Exchange. 1(1.66), 0.559.

Salge, A., Lôbo, S., Siqueira, K., Silva, R., \& Guimarães, J. (2012). Prática da episiotomia e fatores maternos e neonatais relacionados. Revista Eletrônica de Enfermagem. 14(4), 779-785. https ://doi.org/10.5216/ree.v14i4.17538.

Santos, J. d. O., Bolanho, I. C., Mota, J. Q. C. d., Coleoni, L., \& Oliveira, M. A. (2008). Frequência de lesões perineais ocorridas nos partos vaginais em uma instituição hospitalar. Escola Anna Nery Revista de Enfermagem, 12(4), 658-663.

Saxena, R. K., Sandhu, G. S., Babu, K., Bandol, H., \& Sharma, G. V. (2010). Restricted use of episiotomy. The Journal of Obstetrics and Gynecology of India, 60(5), 408.

Shahraki, A. D., Aram, S., Pourkabirian, S., Khodaee, S., \& Choupannejad, S. (2011). A comparison between early maternal and neonatal complications of restrictive episiotomy and routine episiotomy in primiparous vaginal delivery. Journal of Research in Medical Sciences, 16(12), 1583.

Shirvani, M. A., \& Ganji, J. (2014). The influence of cold pack on labour pain relief and birth outcomes: A randomised controlled trial. Journal of Clinical Nursing, 23(17-18), 2473-2480.

Silva, R., Amouzou, A., Munos, M., Marsh, A., Hazel, E., \& Victora, C., \& RMM Working Group. (2016). Can community health workers report accurately on births and deaths? Results of field assessments in Ethiopia, Malawi and Mali. PLOS ONE, 11(1), $\mathrm{e} 0144662$.

Sinclair, A. J., \& Ramsay, I. N. (2011). The psychosocial impact of urinary incontinence in women. The Obstetrician \& Gynaecologist, 13(3), 143-148.

Singh, A., \& Rathore, P. (2011). A comparative study of feto-maternal outcome in instrumental vaginal delivery. The Journal of Obstetrics and Gynecology of India, 61(6), 663-666.

Smith, L. A., Price, N., Simonite, V., \& Burns, E. E. (2013). Incidence of and risk factors for perineal trauma: A prospective observational study. BMC Pregnancy and Childbirth, 13(1), 59.

Sooklim, R., Thinkhamrop, J., Lumbiganon, P., Prasertcharoensuk, W., Pattamadilok, J., Seekorn, K., \& Chansamak, S. (2007). The outcomes of midline versus medio-lateral episiotomy. Reproductive Health, 4(1), 10.

Sorensen, B. L., Rasch, V., Massawe, S., Nyakina, J., Elsass, P., \& Nielsen, B. B. (2011). Advanced life support in obstetrics (ALSO) and post-partum hemorrhage: A prospective 
intervention study in Tanzania. Acta Obstetricia et Gynecologica Scandinavica, 90(6), 609-614.

Spitzer, R. F., Steele, S. J., Caloia, D., Thorne, J., Bocking, A. D., Christoffersen-Deb, A., \& Chemwolo, B. (2014). One-year evaluation of the impact of an emergency obstetric and neonatal care training program in Western Kenya. International Journal of Gynecology \& Obstetrics, 127(2), 189-193.

Stroup, D. F., Berlin, J. A., Morton, S. C., Olkin, I., Williamson, G. D., Rennie, D., \& Thacker, S. B. (2000). Meta-analysis of observational studies in epidemiology. JAMA, 283(15), 2008-2012.

Sulaiman, A. S., Ahmad, S., Ismail, N. A. M., Rahman, R. A., Jamil, M. A., \& Dali, A. Z. M. (2013). A randomized control trial evaluating the prevalence of obstetrical anal sphincter injuries in primigravida in routine versus selective mediolateral episiotomy. Saudi Medical Journal, 34(8), 819-823.

UNICEF. (2008). The state of the world's children 2009: maternal and newborn health. New York: UNICEF.

Verghese, T. S., Champaneria, R., Kapoor, D. S., \& Latthe, P. M. (2016). Obstetric anal sphincter injuries after episiotomy: Systematic review and meta-analysis. International Urogynecology Journal, 27(10), 1459-1467.

Vogt, S. E., Diniz, S. G., Tavares, C. M., Santos, N. C. P., Schneck, C. A., Zorzam, B., \& Dias, M. A. B. (2011). Características da assistência ao trabalho de parto e parto em três modelos de atenção no SUS, no Município de Belo Horizonte, Minas Gerais, Brasil. Cadernos de Saúde Pública, 27, 1789-1800.

Waheed, K., Ejaz, S., \& Aslam, P. (2012). Feto-maternal outcome in operative vaginal delivery. Pakistan Journal of Medical and Health Sciences, 6(4), 1064-1067.

Wai, T. C., Cecilia, C. W., Anny, T. W. M., \& Yee, L. H. (2015). Incidence and risk factors of obstetric anal sphincter injuries after various modes of vaginal deliveries in Chinese women. Chinese Medical Journal, 128(18), 2420.
Wang, X., Li, G.-Y., \& Deng, M.-L. (2014). Pelvic floor muscle training as a persistent nursing intervention: effect on delivery outcome and pelvic floor myodynamia. International Journal of Nursing Sciences, 1(1), 48-52.

World Bank (2014). Country and Lending Groups. Retrieved from http://data.worldbank.org/about/country-and-lending-groups.

World Health Organization. (1997). Care in normal birth: a practical guide. Birth, 24(2), 121-123.

World Health Organization (2003). Surgical care at the district hospital. Geneva: World Health Organization.

World Health Organization (2016). Standards for improving quality of maternal and newborn care in health facilities. Geneva: World Health Organization.

World Health Organization (2018). Maternal mortality fact sheet. Retrieved from http://www.who.int/news-room/fact-sheets/detai 1/maternal-mortality.

World Health Organization \& United Nations Population Fund. (2009). Mental health aspects of women's reproductive health: A global review of the literature. Geneva: World Health Organization.

Yadav, S., Choudhary, D., Narayan, K., Mandal, R. K., Sharma, A., Chauhan, S. S., \& Agrawal, P. (2008). Adverse reproductive outcomes associated with teenage pregnancy. McGill Journal of Medicine: MJM, 11(2), 141.

Zhu, L., Li, L., Lang, J., \& Xu, T. (2012). Prevalence and risk factors for peri-and postpartum urinary incontinence in primiparous women in China: a prospective longitudinal study. International Urogynecology Journal, 23(5), 563-572.

Publisher's Note Springer Nature remains neutral with regard to jurisdictional claims in published maps and institutional affiliations. 